\author{
Federal Reserve Bank of New York \\ Staff Reports
}

\title{
When Does a Central Bank's Balance Sheet Require Fiscal Support?
}

\author{
Marco Del Negro \\ Christopher A. Sims
}

Staff Report No. 701

November 2014

Revised March 2015

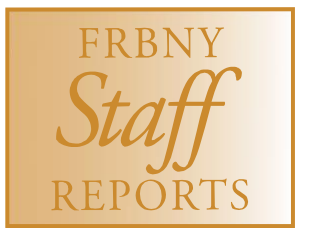

This paper presents preliminary findings and is being distributed to economists and other interested readers solely to stimulate discussion and elicit comments. The views expressed in this paper are those of the authors and do not necessarily reflect the position of the Federal Reserve Bank of New York or the Federal Reserve System. Any errors or omissions are the responsibility of the authors. 


\title{
When Does a Central Bank's Balance Sheet Require Fiscal Support? \\ Marco Del Negro and Christopher A. Sims
}

Federal Reserve Bank of New York Staff Reports, no. 701

November 2014; revised March 2015

JEL classification: E58, E59

\begin{abstract}
Using a simple general equilibrium model, we argue that it would be appropriate for a central bank with a large balance sheet composed of long-duration nominal assets to have access to, and be willing to ask for, support for its balance sheet by the fiscal authority. Otherwise, its ability to control inflation may be at risk. This need for balance sheet support-a within-government transaction - is distinct from the need for fiscal backing of inflation policy that arises even in models where the central bank's balance sheet is merged with that of the rest of the government.
\end{abstract}

Key words: central bank's balance sheet, solvency, monetary policy

Del Negro: Federal Reserve Bank of New York (e-mail: marco.delnegro@ny.frb.org). Sims: Princeton University (e-mail: sims@ @rinceton.edu). This paper was presented at the November 2014 Carnegie-Rochester-NYU Conference on Public Policy. The authors are grateful to their discussant, Ricardo Reis, and to Marvin Goodfriend, the special editor, for their thoughtful suggestions. The authors also thank Fernando Alvarez, Marco Bassetto, Seth Carpenter, Behzad Diba, William Roberds, Andreas Schabert, Oreste Tristani, Harald Uhlig, and participants at various seminars and conferences for very helpful comments. The views expressed in this paper are those of the authors and do not necessarily reflect the position of the Federal Reserve Bank of New York or the Federal Reserve System. 


\section{INTRODUCTION}

Hall and Reis (2013) and Carpenter, Ihrig, Klee, Quinn, and Boote (2013) have explored the likely path of the Federal Reserve System's balance sheet during a possible return to historically normal levels of interest rates. Both conclude that, though a period when the system's net worth at market value is negative might occur, this is unlikely, would be temporary and would not create serious problems. ${ }^{1}$ Those conclusions rely on extrapolating into the future not only a notion of historically normal interest rates, but also of historically normal relationships between interest rates, inflation rates, and components of the System's balance sheet.

In this paper we look at complete, though simplified, economic models in order to study why a central bank's balance sheet matters at all and the consequences of a lack of fiscal support for the central bank. Unlike some of the previous literature, we are not just concerned about periods of zero remittances to the fiscal authority. Rather, we ask whether the lack of fiscal support (that is, a commitment by the fiscal authority never to recapitalize the central bank) implies that the central bank is no longer able to maintain control of inflation, because doing so would lead to its insolvency. These issues are important because they lead us to think about unlikely, but nonetheless possible, sequences of events that could undermine economic stability. As recent events should have taught us, historically abnormal

\footnotetext{
${ }^{1}$ Christensen, Lopez, and Rudebusch (2013) study the interest rate risk faced by the Federal Reserve using probabilities for alternative interest rate scenarios obtained from a dynamic term structure model. They reach the similar conclusions as Hall and Reis (2013) and Carpenter, Ihrig, Klee, Quinn, and Boote (2013). Greenlaw, Hamilton, Hooper, and Mishkin (2013) conduct a similar exercise as Carpenter, Ihrig, Klee, Quinn, and Boote (2013), but also consider scenarios where concern about the solvency of the U.S. government lead to capital losses for the central bank.
} 
events do occur in financial markets, and understanding in advance how they can arise and how to avert or mitigate them is worthwhile. ${ }^{2}$

Constructing a model that allows us to address these issues requires us to specify monetary and fiscal policy behavior and to consider how demand for non-interest-bearing liabilities of the central bank (like currency, or required reserves paying zero interest) responds to interest rates. As we show below, seigniorage plays a central role in determining the possible need for fiscal support for the central bank. But with a given policy in place, seigniorage can vary widely, depending on how sharply demand for cash shrinks as inflation and interest rates rise. An equilibrium model with endogenous demand for cash is therefore required if we are to understand the sources and magnitudes of possible central bank balance sheet problems.

In the first section below we consider a stripped down model to show how the need for fiscal support arises. In subsequent sections we make the model more realistic and try to determine how likely it is that the US Federal Reserve System will need fiscal support. In both the simple model and the more realistic one, we make some of the same generic points.

For the price level to be uniquely determined, fiscal policy must be seen to "back" the price level. Our first point consists in distinguishing this "backing" from what we call fiscal "support". The central bank cannot on its

\footnotetext{
${ }^{2}$ Work by Peter Stella (2005b; 2005a) was among the earliest to bring out the potential importance of central bank balance sheets . A number of recent papers, including Buiter and Rahbari (2012), Corsetti and Dedola (2012), Bassetto and Messer (2013a), Benigno and Nisticó (2014), and Reis (2013), also study the central bank's and the fiscal authorities' balance sheets separately. Bhattarai, Eggertsson, and Gafarov (2013) discuss how the acquisition of long-term government debt by the central banks affects its incentives in terms of setting interest rates. Finally, Quinn and Roberds (2014) provide an interesting account of the demise of the Florin as an international reserve currency in the late 1700s and attribute such demise to the central bank's credit policies and a belated and inadequate recognition that it needed fiscal backing.
} 
own provide fiscal backing. Cochrane (2011) has made this point carefully. Fiscal backing requires that explosive inflationary or deflationary behavior of the price level is seen as impossible because the fiscal authority will respond to very high inflation with higher primary surpluses and to near-zero interest rates with lower, or negative, primary surpluses. But even when fiscal policy is in place that guarantees the price level is uniquely determined and the behavior of inflation is driven by monetary policy, it is nonetheless possible that the central bank, if its balance sheet is sufficiently impaired, may need recapitalization in order to maintain its commitment to a policy rule or an inflation target. Such a recapitalization is a within-government transaction, unrelated to whether fiscal backing is present. Fiscal "support" is what we call a commitment by the treasury to recapitalize the central bank if necessary. Without fiscal support, a central bank that could otherwise implement its policy rule or hit its inflation target, may find that it must allow more inflation than it would like.

Second, a central bank's ability to earn seigniorage can make it possible for it to recover from a situation of negative net worth at market value without recapitalization from the treasury, while still maintaining its policy rule. Whether it can do so depends on the policy rule, the demand for its non-interest-bearing liabilities, and the size of the initial net worth gap. ${ }^{3}$

Last, in the presence of a large long-duration balance sheet, a central bank that is committed to avoiding any request for fiscal support (or a fiscal authority committed to providing none) can open the door to indeterminacy via self-fulfilling equilibria. Expectations of high inflation in the future can lead to capital losses that need to be filled by generating seigniorage, thereby validating the expectations.

\footnotetext{
${ }^{3}$ Berriel and Bhattarai (2009) study optimal policy in a setting where the central bank and the fiscal authority have separate budget constraints. Berriel and Bhattarai (2009) only consider the case where the central bank can acquire short-term assets however, which implies that solvency issues are unlikely to arise (see Bassetto and Messer (2013b)).
} 
II. THE SIMPLE MODEL

We first consider a stripped-down model to illustrate the principles at work. A representative agent solves

$$
\begin{gathered}
\max _{C, B, M, F} \int_{0}^{\infty} e^{-\beta t} \log \left(C_{t}\right) d t \quad \text { subject to } \\
C_{t} \cdot\left(1+\psi\left(v_{t}\right)\right)+\frac{\dot{B}+\dot{M}}{P_{t}}+\tau_{t}+F_{t}=\rho F_{t}+\frac{r_{t} B_{t}}{P_{t}}+Y_{t},
\end{gathered}
$$

where $C$ is consumption, $B$ is instantaneous nominal bonds paying interest at the rate $r, M$ is non-interest-bearing money, $\rho$ is a real rate of return on a real asset $F, Y$ is endowment income, and $\tau$ is the primary surplus (or simply lump-sum taxes, since we have no explicit government spending in this model). Velocity $v_{t}$ is given by

$$
v_{t}=\frac{P_{t} C_{t}}{M_{t}}, v_{t} \geq 0
$$

and the function $\psi(),. \psi^{\prime}()>$.0 captures transaction costs.

The government budget constraint is

$$
\frac{\dot{B}+\dot{M}}{P_{t}}+\tau_{t}=\frac{r_{t} B_{t}}{P_{t}}
$$

Monetary policy is an interest-smoothing Taylor rule:

$$
\dot{r}=\theta_{r} \cdot\left(\bar{r}+\theta_{\pi}\left(\frac{\dot{P}}{P}-\bar{\pi}\right)-r\right) .
$$

The "Taylor Principle", that $\theta_{\pi}$ should exceed one, is the usual prescription for "active" monetary policy. The effective short term interest rate is given by the maximum of $r_{t}$ and the lower bound on interest rates $\underline{r}$ :

$$
r_{t}^{\mathrm{e}}=\max \left(r_{t}, \underline{r}\right)
$$


First order conditions for the private agent are

$$
\begin{array}{ll}
\partial C: & \frac{1}{C}=\lambda\left(1+\psi+\psi^{\prime} v\right) \\
\partial F: & -\hat{\dot{\lambda}}=\lambda(\rho-\beta) \\
\partial B: & -\frac{\hat{\dot{\lambda}}}{P}+\beta \frac{\lambda}{P}+\frac{\lambda}{P} \frac{\hat{\dot{P}}}{P}=r \frac{\lambda}{P} \\
\partial M: & -\frac{\hat{\dot{\lambda}}}{P}+\beta \frac{\lambda}{P}+\frac{\lambda}{P} \frac{\hat{\dot{P}}}{P}=\frac{\lambda}{P} \psi^{\prime} v^{2}
\end{array}
$$

The $\hat{\dot{z}}_{t}$ notation means the time derivative of the future expected path of $z$ at $t$. It exists even at dates when $z$ has taken a jump, so long as its future path is right-differentiable. Below we also use the $\frac{\hat{d}^{+}}{d t}$ operator for the same concept.

We are taking the real rate $\rho$ as exogenous, and in this simple version of the model constant. The economy is therefore being modeled as either having a constant-returns-to scale investment technology or as having access to international borrowing and lending at a fixed rate. Though we could extend the model to consider stochastically evolving $Y, \rho$, and other external disturbances, here we consider only surprise shifts at the $t=0$ starting date, with perfect-foresight deterministic paths thereafter. This makes it easier to follow the logic, though it makes the time- 0 adjustments unrealistically abrupt.

Besides the exogenous influences that already appear explicitly in the system above ( $\rho$ and $Y$ ), we consider an "inflation scare" ${ }^{4}$ variable $x$. This enters the agents' first order condition as a perturbation to inflation expectations. It can be reconciled with rational expectations by supposing that agents think there is a possibility of discontinuous jumps in the price level, with these jumps arriving as a Poisson process with a fixed rate. This would happen if at these jump dates monetary policy created discontinuous jumps

\footnotetext{
${ }^{4}$ Goodfriend (1993) coined the term "inflation scare" for a phenomenon like what we model here and pointed to historical episodes where they seem to have occurred.
} 
in $M$. Such jumps would create temporary declines in the real value of government debt $B / P$ and would generate seigniorage, which might explain why such jumps are perceived as possible. If the jump process doesn't change after a jump occurs, there is no variation in velocity, the inflation rate, consumption, or the interest rate at the jump dates. We consider two versions of an inflation scare: One in which the public is correct about the occurrence of occasional randomly timed price level jumps (so seigniorage is higher) and one in which they are incorrect, with central bank policy sticking to the Taylor rule at all times. In the latter case, of course, private agents would eventually be likely to revise their expectations, and we do not formally model that. But since the public's beliefs are consistent with no price jumps over any finite span of time, there is no logical problem with assuming that they hold to those beliefs over a long period of time with no price jumps.

The inflation scare variable changes the first order conditions above to give us

$$
\begin{aligned}
\text { дв: } & -\hat{\hat{\lambda}} \frac{1}{P}+\beta \frac{\lambda}{P}+\frac{\lambda}{P}\left(\frac{\hat{\dot{P}}}{P}+x\right)=r \frac{\lambda}{P} \\
\partial M: & -\hat{\dot{\lambda}} \frac{1}{P}+\beta \frac{\lambda}{P}+\frac{\lambda}{P}\left(\frac{\hat{P}}{P}+x\right)=\frac{\lambda}{P} \psi^{\prime} v^{2}
\end{aligned}
$$

Because the price and money jumps have no effect on interest rates or consumption, no other equations in the model need change. These first order conditions reflect the private agents' use of a probability model that includes jumps in evaluating their objective function.

We can solve the model analytically to see the impact of an unanticipated, permanent, time- 0 shift in $\rho$ (the real rate of return), $x$ (the inflation scare variable), or $\bar{r}$ (the central bank's interest-rate target). We could also 
solve it numerically for arbitrary time paths of $\rho, x, \bar{r}$, et cetera, but we reserve such exercises for the more detailed and realistic model in subsequent sections.

Solving to eliminate the Lagrange multipliers from the first order conditions we obtain

$$
\begin{gathered}
\rho=r-\frac{\hat{P}}{P}-x \\
r=\psi^{\prime}(v) v^{2} \\
-\frac{\hat{d^{+}}}{d t}\left(\frac{1}{C \cdot\left(1+\psi+\psi^{\prime} v\right)}\right)=\frac{\rho-\beta}{C\left(1+\psi+\psi^{\prime} v\right)} .
\end{gathered}
$$

Using (11) and the policy rule (5), we obtain that along the path after the initial date,

$$
\begin{aligned}
\dot{r}=\theta_{r} \cdot\left(\left(\theta_{\pi}(r-\rho-x)\right.\right. & \left.-r+\bar{r}-\theta_{\pi} \bar{\pi}\right) \\
& =\theta_{r} \cdot\left(\theta_{\pi}-1\right) r-\theta_{r} \theta_{\pi}(\rho+x)+\theta_{r}\left(\bar{r}-\theta_{\pi} \bar{\pi}\right) .
\end{aligned}
$$

With the usual assumption of active monetary policy, $\theta_{\pi}>1$, so this is an unstable differential equation in the single endogenous variable $r$. Solutions are of the form

$$
r_{t}=E_{t}\left[\int_{0}^{\infty} e^{-\left(\theta_{\pi}-1\right) \theta_{r} s} \theta_{r} \theta_{\pi}\left(\rho_{t+s}+x_{t+s}\right) d s\right]-\frac{\bar{r}-\theta_{\pi} \bar{\pi}}{\theta_{\pi}-1}+\kappa e^{\left(\theta_{\pi}-1\right) \theta_{r} t} .
$$

In a steady state with $x$ and $\rho$ constant (and $\kappa=0$ ), this give us

$$
r=\frac{\theta_{\pi}(\rho+x)}{\theta_{\pi}-1}-\frac{\bar{r}-\theta_{\pi} \bar{\pi}}{\theta_{\pi}-1} .
$$

From (12) we can find $v$ as a function of $r$. Substituting the government budget constraint into the private budget constraint gives us the social resource constraint

$$
C \cdot(1+\psi(v))+\dot{F}=\rho F+Y .
$$

Solving this unstable differential equation forward gives us

$$
F_{t}=E_{t}\left[\int_{0}^{\infty} \exp \left(-\int_{0}^{s} \rho_{t+v} d v\right)\left(Y_{t+s}-C_{t+s}\left(1+\psi\left(v_{t+s}\right)\right)\right) d s\right] .
$$


Here we do not include an exponentially explosive term because that would be ruled out by transversality in the agent's problem and by a lower bound on $F$. With constant $\rho, x$ and $Y, r$ and $v$ are constant, and (13) then lets us conclude that $C$ grows (or shrinks) steadily at the rate $\rho-\beta$. We can therefore use (18) to conclude that along the solution path, since $\rho, Y$ and $v$ are constant

$$
C_{t}=\frac{\beta \cdot\left(\rho^{-1} \Upsilon+F_{t}\right)}{1+\psi(v)}
$$

This lets us determine initial $C_{0}$ from the $F_{0}$ at that date. From then on $C_{t}$ grows or shrinks at the rate $\rho-\beta$ and the resulting saving or dissaving determines the path of $F_{t}$ from (19).

Whether in steady state or not, knowing the time path of $r$ (as a function of $\kappa$ ) from (15) gives us the time path for $v$ from (12), for $C$ from (18) and (13) and then real balances $m$ from the definition of $v$. We then get inflation from (11). But a time path for inflation does not give us a value for $P_{0}$, the initial price level. The indeterminacy in $P$ is only through its dependence on $\kappa$, however. We interpret the Taylor rule (5) as not forward-looking that is, it holds locally, with left and right derivatives equal, at all dates, including the initial date. But this assumed differentiability applies to the linear combination of derivatives that appear in the equation: $\dot{r}-\theta_{r} \theta_{\pi} \dot{P} / P$. Thus while the equation implies $r-\log P$ is differentiable from left and right even at time zero, it does not constrain $r$ and $P$ individually from jumping. Our solution for $r$ as given in (15) is forward-looking and generally implies an initial discontinuous jump in $r$ at time 0 . The Taylor rule then determines a corresponding initial jump in the price level, determining $P_{0}-$ except that, because $\kappa$ enters (15), $P_{0}$ depends on $\kappa$. Note that whenever $\kappa \neq 0, r$ eventually explodes at an exponential rate, implying via (11) that inflation (not the price level) explodes exponentially. 


\section{FISCAL BACKING AND FISCAL SUPPORT}

The literature on the fiscal theory of the price level has shown that monetary policy alone cannot uniquely determine the price level without appropriate fiscal backing (Cochrane, 2011). This literature, though, for the most part distinguishes monetary policy and fiscal policy only by what variables they control - interest rates or money growth for the former, taxes and spending for the latter. The government is treated as having a unified budget constraint, with no separate accounting of assets and liabilities of the central bank vs. those of the fiscal authority.

The model of the previous section, which we will identify as the "simple model", also has only a unified government budget constraint. Furthermore, we have so far specified only a government budget constraint, not a fiscal policy rule. In this model, and in the more complex model discussed below, the insights of the fiscal theory of the price level apply. A Taylor rule monetary policy, even if it satisfies the $\theta_{\pi}>1$ condition, cannot by itself uniquely determine the price level. This is reflected in the fact that we cannot rule out $\kappa \neq 0$ in (15) in equilibrium.

Though this point about non-uniqueness of the price level is by now well known (if not completely non-controversial), the fiscal "support" we are discussing in this paper is not the fiscal "backing" whose necessity is brought out in the fiscal theory of the price level. To pin down a unique price level requires a fiscal policy - in this model a rule for setting the primary surplus - that provides the backing. Under some conditions, fiscal backing can take a form that forces $\kappa$ to zero, and hence leaves the time path of prices to be determined by monetary policy, without reference to the details of the fiscal policy rule.

Most of the analysis in this paper assumes that fiscal backing is present and determines $\kappa$ uniquely, in most but not all cases determines it uniquely 
as zero. Yet we still discuss the need for fiscal "support", because we consider a central bank balance sheet and budget in addition to those of the unified government. Fiscal support is needed when the central bank cannot maintain its desired inflation policy or its policy rule without a capital injection from the treasury. Since such a capital injection would most naturally take the form of transferring nominal, interest-bearing government bonds from the treasury to the central bank, the unified government budget and balance sheet would net out the transaction. And indeed, if the transaction took place automatically and smoothly, it would be of no concern to policy. But in some countries and time periods, including perhaps the US now, the need for a fiscal transfer for recapitalization could have important political economy consequences, particularly for central bank independence.

We defer to the appendix detailed discussion of the fiscal policies that can deliver a unique value of $\kappa$ in our model, but discuss the issue informally here. As we have already verified, the simple model without specifying a fiscal policy rule delivers the conclusion that the price level either follows a path with stable inflation, or, with $\kappa \neq 0$ follows a path with inflation exploding. Economists often rule out highly explosive solutions to dynamic models by an appeal to "transversality" and "no-Ponzi" conditions. Why does that not work here?

Transversality conditions are implications of dynamic optimization. They rule out model solutions in which wealth grows without bound, while expenditures that deliver utility remain bounded or grow much more slowly. In the simple model, the transversality condition of the private agent requires that private wealth in the form of real government debt $B / P$ not grow, relative to $C \cdot\left(1+\psi+\psi^{\prime} v\right)$, at faster than the discount rate $\beta$. But the model solutions in which $\kappa \neq 0$ imply only that nominal interest rates and inflation explode. With some forms of fiscal policy, the real value of government debt remains stable despite the explosion in nominal rates and 
inflation. Transversality, which rules out rapidly growing wealth, and noPonzi conditions, which rule out paths on which the public starts borrowing from the government instead of investing in its debt, are then satisfied even on the explosive paths.

In order to deliver a unique value of $\mathcal{k}$ when monetary policy follows a Taylor rule with $\theta_{\pi}>1$, fiscal policy, which conventionally is specified as not depending on inflation, must be seen as responsive to inflation, at least at very high and very low rates of inflation. Fiscal policy must tighten in response to increased inflation at high inflation rates, and loosen (run deficits) at low inflation rates, as deflation approaches $-\rho$. If it is seen as committed to respond this way, it can eliminate all the $\kappa \neq 0$ equilibria, thereby ensuring stable inflation, and thus never requiring that inflation reach levels that impact fiscal policy in equilibrium. ${ }^{5}$

\section{HOW COULD A CENTRAL BANK BE "INSOLVENT"?}

A central bank in an economy with fiat money by definition can always pay its bills by printing money. In that sense it cannot be insolvent. On the other hand, paying its bills by printing money clearly could interfere with the policy objectives of the central bank, assuming it wants to control inflation. Historically there were central banks (like the US Federal Reserve in previous decades) whose liabilities were all reasonably characterized as "money". There was currency, which paid no interest, and also reserve deposits, which also paid no interest. For such a central bank it is easy to

\footnotetext{
${ }^{5}$ Cochrane (2011) might seem to contradict this paragraph's assertion, as he apparently suggests that there is no way for a Taylor rule to deliver a determinate price level. He agrees, though, that there are fiscal policies that will deliver a determinate price level. Where he might disagree is on whether policies like those we propose in the appendix, which commit to actions at high and low inflation levels that are not observed in equilibrium, can be credibly implemented.
} 
understand that "paying bills by printing money" could conflict with "restricting money growth to control inflation".

Modern central banks, though, have interest-bearing reserve deposit liabilities as well as non-interest-bearing ones. Furthermore, in the last several years central banks have demonstrated that they can rapidly expand their reserve deposit liabilities without generating strong inflationary pressure. Such central banks can "print" interest-bearing reserves. What prevents them from meeting any payment obligations they face by creating interestbearing reserve deposits?

The recent non-inflationary balance sheet expansions have arisen through central bank purchases of interest-earning assets by issuing interest-bearing reserves. If instead it met payment obligations - staff salaries, plant and equipment, or interest on reserves - by issuing new interest-bearing reserve deposits, there would be no flow of earnings from assets offsetting the new flow of interest on reserves. If this went on long enough, interestbearing liabilities would come to exceed interest-bearing assets. To the extent the gap between interest earnings and interest-bearing obligations was not covered by seignorage, the bank's net liabilities would begin growing at approximately the interest rate.

In this scenario, the private sector would be holding an asset - reserves - that was growing at the real interest rate. This might be sustainable if there were some offsetting private sector liability growing at the same rate - expected future taxes, or bonds issued by the private sector and bought by the government, for example. But if we rule out these possibilities, by saying real taxes are bounded and the fiscal authority will not accumulate an exponentially growing cache of private sector debt, the exploding liabilities of the central bank violate the private sector's transversality condition. In other words, private individuals, finding their assets growing so rapidly, would try to turn those assets into consumption goods. Or in still other 
words, the exploding interest-bearing liabilities of the central bank would eventually cause inflation, even if money supply growth were kept low.

This conclusion is a special case of the usual analysis in the fiscal theory of the price level: increased issue of nominal bonds, unbacked by taxation, is eventually inflationary, regardless of monetary policy.

\section{CAPITAL LOSSES FROM INTEREST RATE INCREASES IN THE SIMPLE}

MODEL

In this section we show how the central bank balance sheet and capital needs respond to one-time, unanticipated increases in the interest rate, with two different assumptions on the source of the interest rate change. In one the real rate changes, while in the other the nominal rate changes because of an inflation scare, with no change in the real rate.

We are interested in determining the effects of these one-time disturbances in exogenous elements of the model on the central bank balance sheet and on the sustainability of its policy rule. We need therefore to specify the central bank's balance sheet. We assume that it holds as assets nominal government debt, in the nominal amount $B^{C}$. It has non-interestbearing liabilities $M$ (currency) and interest-bearing liabilities (reserves) $V$. The assets have duration $\omega>0$. We assume that along the perfect-foresight equilibrium path $V$ and $B^{C}$ pay the same rate of return, but since $V$ are assumed to be demand liabilities (deposits) with duration 0 , their value is not affected by changes in interest rates. We hold for later, in the discussion of the larger model, precise specification of the maturity structure of the debt. For our comparative steady state calculation what matters is only that when, unexpectedly, the interest rate changes from one constant level $r$ to a new constant level $r^{\prime}$, the price $q$ of assets of duration $\omega$ changes by a factor $(\omega r+1) /\left(\omega r^{\prime}+1\right)$. A need for recapitalization arises when $q B^{C}-V$ becomes negative, while the discounted present value of seigniorage remains 
too small to cover the gap. For comparison of steady states in this simple model, the discounted present value of seigniorage is $M_{0} \pi / r$, where all variables are at their time-zero values after any initial discontinuous jumps.

To make the calculations, we need to specify the form of $\psi(v)$, the transactions cost function. We choose the form

$$
\psi(v)=\psi_{0} e^{-\psi_{1} / v} .
$$

Our reasons for choosing this functional form, and the extent of its claim to realism, are discussed below in the context of the detailed model. We use $\psi_{0}=50, \psi_{1}=103$. The $\psi_{1}$ value matches the base case of the detailed model, while the $\psi_{0}$ value is adjusted to reflect the fact that here we normalize $Y$ and $M$ to 1 . We set the policy parameters $\theta_{\pi}=1.5, \theta_{r}=1, \bar{r}=\rho$, $\bar{\pi}=.005$. It is also assumed that $Y=1, F_{0}=0$, and initial $M=1$.

First we look at a change from $\rho=\beta=\bar{r}=.01$ to $\rho=\beta=.02$. This is meant to crudely approximate an interest rate increase arising out of a cyclical recovery. We increase $\beta$ and $\rho$ together because in our setup, with a fixed real rate, changing the gap between $\rho$ and $\beta$ has large effects on initial savings and consumption that would not be nearly as strong if we had a model with endogenous real rate.

Table 1 shows that such a rise in real rate can have a big impact on the balance sheet, yet nonetheless require no capital injection. Asset values decline by $7 \%$ to $32 \%$, depending on duration. Interest-bearing liabilities rise and nominal balances fall as private agents reduce money holdings in response to the higher interest rates. This is enough to push the central bank's assets below $V$, meaning that net interest earnings will be negative in the new steady state, but only when $B^{C} / M$ is six times $M$ and with durations longer than 5 years or, marginally, when duration is 20 and asets are 3 times $M$. Yet, despite the large interest earnings gap, amounting in present value to nearly the value of outstanding currency in the case 
CENTRAL BANK'S BALANCE SHEET

TABLE 1. Change in steady state after real rate rise

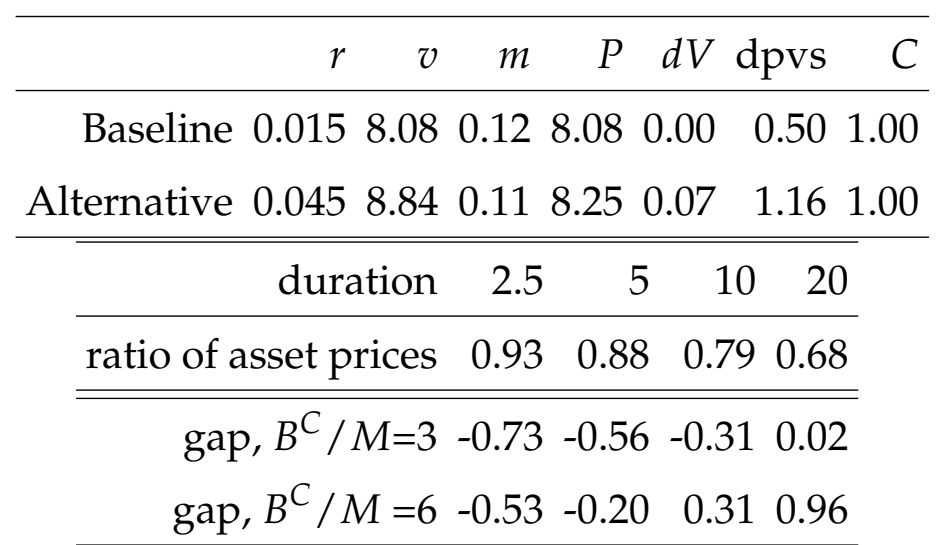

Notes: $r$ : nominal interest rate; $v$ : velocity; $m$ : real balances; $P$ : price level; $d V$ : change in the level of interest bearing liabilities $V$; dpvs: discounted present value of seigniorage; $C$ : consumption; $B^{C} / M$ : ratio of assets $B^{C}$ to non-interest bearing liabilities $M$; gap: discounted present value of seigniorage required to avoid a need for recapitalization. Numbers are from comparing steady states of this paper's simple model with $\theta_{\pi}=1.5, \theta_{r}=1, \psi_{0}=50, \psi_{1}=103, \bar{\pi}=.005, \bar{r}=.015$, and $x=0$, while real rate $\rho$ and discount rate $\beta$ increase from .01 to .02 .

of $B^{C} / M=6$ and duration of 20 years, the new equilibrium generates so much additional seigniorage (more than double that in the original steady state) that no capital injection is required for any of the durations or balance sheet levels shown.

The new steady state in this scenario has higher inflation, because we have assumed that $\bar{r}$, the target nominal rate in the Taylor rule, remains at its old level. If instead we had increased $\bar{r}$ along with $\rho$ and $\beta$, the increase in seigniorage would have been much less, but there would also be a smaller initial decline in asset values, and this latter effect predominates. All the entries in the "gap" table would be negative in that case.

This result illustrates a general phenomenon tending to limit the need for central bank recapitalization as asset values fluctuate with interest rates. Higher interest rates reduce asset values, but they tend to go with higher future inflation, which increases seigniorage. Disturbances that generate a need for recapitalization would have to lower asset values without any commensurate increase in future seigniorage. This can happen, and does 
happen, when bad judgment or political pressure leads a central bank to invest in assets of insolvent private entities, but our formal model does not take up this possibility.

An inflation scare scenario, however, is capable of generating an interest rate rise without corresponding future inflation. A mistaken belief by the public that the central bank will at random future times create jumps in the price level will raise current interest rates. If the central bank does not in fact create the expected jumps in the price level, there will be no corresponding increase in future seigniorage. In Table $2 x$ jumps up to .05 at time 0 and $\bar{r}$, the central bank's nominal rate target, jumps by the same amount (which keeps actual inflation from changing).

TABLE 2. Change in steady state after $5 \%$ inflation scare

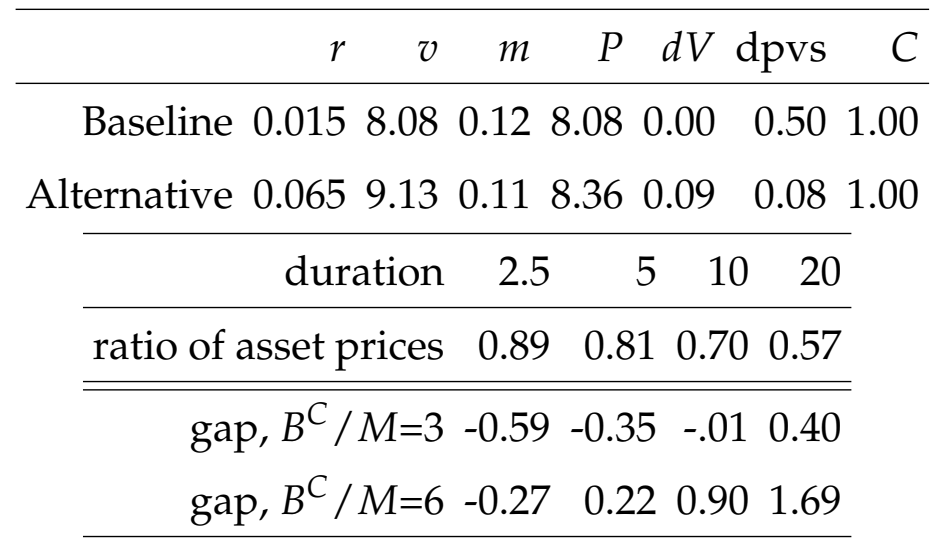

Notes: See notes to Table 1 for variable definitions. Here parameter values are as in that table, except that $\rho$ and $\beta$ are kept constant at .01, while the inflation scare variable $x$ increases from 0 to .05 and $\bar{r}$ increases by the same amount.

The gap lines in this table show positive entries for long durations and large balance sheets. And in this case, the discounted present value of seigniorage drops drastically, so that it covers the gap in none of the cases where the gap is positive. This inflation scare is large, and the problems show up only at balance sheet durations considerably longer than or balance sheet sizes relative to currency considerably larger than prevail currently for the Federal Reserve system, but they show that a strong enough 
fear of future inflation could require a central bank with a large enough, high-duration balance sheet to obtain a capital injection.

In cases where the gap is not covered by seigniorage in this equilibrium, the gap would be covered in some cases if the central bank actually behaved the way the public expects it to, occasionally generating randomly timed jumps in the price level. The expected discounted present value of seignorage is the initial value of $M$ (after expectations have adjusted) times $\pi /(\rho+x)$ if the central bank does not allow the price jumps, but simply $\pi / \rho$ if it does allow the price jumps. It would rise from the .07 shown in the table to .43 , which would cover the gap for some combinations of balance sheet size and duration in the table. Furthermore, in the cases where validating expectations would not raise enough seigniorage to cover the gap, the gap could be covered if the central bank jumped the price level somewhat more often or by larger amounts than expected. In any case where a capital injection is required without price jumps, then, the central bank would have two choices: seek a capital injection, or validate the public's expectation of high future seigniorage and inflation.

If the central bank's policy rule is to stick to its Taylor rule so long as that requires no capital injection, but to use random price jumps to generate seigniorage whenever a capital injection would otherwise be required, there are therefore (at least) two possible equilibria. In one, the public believes that the Taylor rule, with no price jumps, will prevail forever, and it does. In the other, the public believes that the central bank will generate future seigniorage via occasional price jumps, and the central bank finds that it must do so to avoid the need for a capital injection.

While this example with discontinuous price jumps may seem artificial, it illustrates a general point. A central bank can usually produce more seigniorage by increasing inflation. A public belief that inflation might be higher in the future will raise interest rates, and thereby reduce asset values 
on the central bank's balance sheet. If the public recognizes that balance sheet problems might lead the central bank to tolerate higher inflation in order to avoid the need for fiscal support, this can create multiple equilibria. Different expectations by the public can induce different policy behavior that validates those expectations.

This simple model has omitted two sources of seigniorage, population growth and technical progress. It therefore makes it unrealistically easy to find conditions in which fiscal support is required. The analytic solution for steady states that we have used for Tables 1 and 2 can be extended to allow considering more plausible exogenous, non-constant time paths of $\rho, x$, etc., but only with use of numerical integration. Below we expand the model to include these extra elements and calibrate the parameters and the nature of the shocks more carefully to the situation of the US Federal Reserve. Of course our ability to calibrate is limited by the sensitivity of results to the transactions cost function. We have little relevant historical experience with currency demand at low or very high interest rates. Rates were very low in the 1930's and the early 1950's, but the technology for making non-currency transactions is very different now. It is difficult to predict how much and how fast people would shift toward, say, interest-bearing pre-loaded cash cards as currency replacements if interest rates increased to historically normal levels. We can at best show ranges of plausible results.

\section{THE FULL MODEL}

Like the simple model, this one borrows from Sims (2005). The household planner (whose utility includes that of offspring, see Barro and Sala-i Martin (2004)) maximizes:

$$
\int_{0}^{\infty} e^{-(\beta-n) t} \log \left(C_{t}\right) d t
$$


where $C_{t}$ is per capita consumption, $\beta$ is the discount rate, and $n$ is population growth, subject to the budget constraint:

$$
\begin{aligned}
& C_{t}\left(1+\psi\left(v_{t}\right)\right)+\dot{F}_{t}^{P}+\frac{\dot{V}_{t}+\dot{M}_{t}+q_{t} \dot{B}^{P}}{P_{t}}= \\
& \gamma^{\gamma t}+\left(\rho_{t}-n\right) F_{t}^{P}+\left(r_{t}-n\right) \frac{V_{t}}{P_{t}}+\left(\chi+\delta-q_{t} \delta-n\right) \frac{B^{P}}{P}-n \frac{M_{t}}{P_{t}}-\tau_{t} .
\end{aligned}
$$

We express all variables in per-capita terms and initial population is normalized to one. $F_{t}^{P}$ and $B_{t}^{P}$ are foreign assets and long-term government bonds in the hand of the public, respectively, $V_{t}$ denotes central bank reserves, $M_{t}$ is currency, $\tau_{t}$ is lump-sum taxes, $Y$ is an exogenous income stream growing at rate $\gamma$. Foreign assets and central bank reserves pay an exogenous real return $\rho$ and a nominal return $r_{t}$, respectively. Long term bonds are modeled as in Woodford (2001). They are assumed to depreciate at rate $\delta\left(\delta^{-1}\right.$ captures the bonds average duration) and pay a nominal coupon $\chi+\delta .^{6}$

The government is divided into two distinct agencies called "central bank" and "fiscal authority". The central bank's budget constraint is

$$
\begin{aligned}
\left(q_{t} \frac{\dot{B}^{C}}{P_{t}}-\frac{\dot{V}_{t}+\dot{M}_{t}}{P_{t}}\right) e^{n t} \\
\quad=\left(\left(\chi+\delta-\delta q_{t}-n q_{t}\right) \frac{B^{C}}{P}-\left(r_{t}-n\right) \frac{V_{t}}{P_{t}}+n \frac{M_{t}}{P_{t}}-\tau_{t}^{C}\right) e^{n t}
\end{aligned}
$$

where $B_{t}^{C}$ are long-term government bonds owned by the central bank, and $\tau_{t}^{C}$ are remittances from the central bank to the fiscal authority. The central bank is assumed to follow the rule (5) for setting $r_{t}$, the interest on reserves. We also assume that the central bank's policy in terms of the asset side of its balance sheet $B_{t}^{C}$ consists in an exogenous process $B_{t}^{C}=\bar{B}_{t}^{C}$. Finally, the central bank is also assumed to follow a rule for remittances, which we discuss in section VI.2. We explain there why neither the rule for $B_{t}^{C}$ nor that for remittances will play a central role in our analysis.

\footnotetext{
${ }^{6}$ We write the coupon as $\chi+\delta$ so that at steady state if $\chi$ equals the short term rate the bonds sell at $\operatorname{par}(q=1)$.
} 
Solving the central bank's budget constraint forward we can obtain its intertemporal budget constraint:

$$
q \frac{B_{0}^{C}}{P_{0}}-\frac{V_{0}}{P_{0}}+\int_{0}^{\infty}\left(\frac{\dot{M}_{t}}{M_{t}}+n\right) \frac{M_{t}}{P_{t}} e^{-\int_{0}^{t}\left(\rho_{s}+x_{s}-n\right) d s} d t=\int_{0}^{\infty} \tau_{t}^{C} e^{-\int_{0}^{t}\left(\rho_{s}+x_{s}-n\right) d s} d t
$$

where $x_{s}$ refers to the inflation scare variable discussed in section II (the inflation scare results in a premium increasing the real returns on all nominal assets, and hence enters the central bank's present discounted value calculations). Equation (24) shows that, regardless of the rule for remittances, their discounted present value $\int_{0}^{\infty} \tau_{t}^{C} e^{-\int_{0}^{t}\left(\rho_{s}+x_{s}-n\right) d s} d t$ has to equal its left hand side, namely the market value of assets minus reserves plus the discounted present value of seigniorage $\int_{0}^{\infty}\left(\frac{\dot{M}_{t}}{M_{t}}+n\right) \frac{M_{t}}{P_{t}} e^{-\int_{0}^{t}\left(\rho_{s}+x_{s}-n\right) d s} d t$. We can also compute the constant level of remittances $\bar{\tau}^{C} e^{\gamma t}$ (taking productivity growth into account) that satisfies expression (24).

$$
\begin{aligned}
& \bar{\tau}^{C}=\left(\int_{0}^{\infty} e^{(\gamma+n) t-\int_{0}^{t}\left(\rho_{s}+x_{s}\right) d s} d t\right)^{-1} \\
& \left(q \frac{B^{c}}{P}-\frac{V}{P}+\int_{0}^{\infty}\left(\frac{\dot{M}_{t}}{M_{t}}+n\right) \frac{M_{t}}{P_{t}} e^{-\int_{0}^{t}\left(\rho_{s}+x_{s}-n\right) d s} d t\right) .
\end{aligned}
$$

Government debt is assumed to be held either by the central bank or the public: $B_{t}=B_{t}^{C}+B_{t}^{P}$. The budget constraint of the fiscal authority is

$$
\left(G_{t}-\tau_{t}+\left(\chi+\delta-\delta q_{t}-n q_{t}\right) \frac{B}{P}\right) e^{n t}=\left(\tau_{t}^{C}+q_{t} \frac{\dot{B}}{P_{t}}\right) e^{n t}
$$

where $G_{t}$ is government spending. The rule for $\tau_{t}$ is given by:

$$
\tau_{t}=\phi_{0} e^{\gamma t}+\left(\phi_{1}+n+\gamma\right) q \frac{B}{P} \text {. }
$$

This rule makes the debt to GDP ratio $b_{t}=q \frac{B}{P} e^{-\gamma t}$ converge as long as $\phi_{1}>\beta-n$. The initial level of foreign assets in the hand of the public, central bank reserves, and currency are $F_{0}^{P}, V_{0}$, and $M_{0}$, respectively. 
As in the simple model the first order condition for the household's problem with respect to $C, F^{P}, B, V$, and $M$ yield the Euler equation (13), the Fisher equation (11), ${ }^{7}$ the money demand equation (12), and the arbitrage condition between reserves and long-term bonds:

$$
\frac{\chi+\delta}{q}-\delta+\frac{\dot{q}}{q}=r
$$

The solutions for $r$ is given by equation (15), and those for inflation $\frac{\dot{P}}{P}$ and velocity $v$ follow from equations (11) and (12), respectively. The growth rate of consumption $\frac{\dot{C}}{C}$, is given by

$$
\frac{\dot{C}}{C}=(\rho-\beta)-\frac{2 \psi^{\prime}(v)+v \psi^{\prime \prime}(v)}{1+\psi(v)+v \psi^{\prime}(v)} \dot{v},
$$

which obtains from differentiating expression (13). Differentiating the definition of velocity (3) we obtain an expression for the growth rate of currency:

$$
\frac{\dot{M}}{M}=\frac{\dot{P}}{P}+\frac{\dot{C}}{C}-\frac{\dot{v}}{v}
$$

The economy's resource constraint is given by

$$
C(1+\psi(v))+\dot{F}=(Y-G) e^{\gamma t}+(\rho-n) F,
$$

where $F=F^{P}+F^{C}$ is the aggregate amount of foreign assets held in the economy (we assume that the central banks foreign reserves $F^{C}$ are zero), and where we assumed $G_{t}=G e^{\gamma t}$. Solving this equation forward we obtain a solution for consumption in the initial period:

$$
C_{0}\left(\int_{0}^{\infty}(1+\psi(v)) e^{-\int_{0}^{t}\left(\rho_{s}-\frac{\dot{C}}{C}-n\right) d s} d t\right)=F_{0}+(Y-g) \int_{0}^{\infty} e^{(\gamma+n) t-\int_{0}^{t} \rho_{s} d s} d t
$$

\footnotetext{
${ }^{7}$ Note that short term debt was called $B$ in the simple model, and was issued by the fiscal authority. Here it is called $V$, and is issued by the central bank.
} 
Given velocity $v$ and the level of consumption, we can compute real money balances $\frac{M}{P}$, the initial price level $P_{0}$, and seigniorage $\frac{\dot{M}}{P}+n \frac{M}{P}=\left(\frac{\dot{M}}{M}+n\right) \frac{M}{P}$ (using (30)), and the present discounted value of seigniorage

$$
\int_{0}^{\infty}\left(\frac{\dot{M}}{M}+n\right) \frac{M}{P} e^{-\int_{0}^{t}\left(\rho_{s}+x_{s}-n\right) d s} d t=c_{0} \int_{0}^{\infty}\left(\frac{\dot{M}}{M}+n\right) v^{-1} e^{-\int_{0}^{t}\left(\rho_{s}+x_{s}-\frac{\dot{C}}{C}-n\right) d s} d t .
$$

Finally, solving (28) forward we find the current nominal value of long-term bonds

$$
q_{0}=(\chi+\delta) \int_{0}^{\infty} e^{-\left(\int_{0}^{t} r_{s} d s+\delta t\right)} d t
$$

VI.1. Steady state. At a steady state where $\bar{\rho}=\beta+\gamma, \bar{r}=\bar{\rho}+\bar{\pi}, \bar{v}$ satisfies $\bar{v}^{2} \psi^{\prime}(\overline{\mathcal{v}})=r_{s s}$. Steady state consumption is given by $\bar{C}_{t}=\bar{C}_{0} e^{\gamma t}$ where $\bar{C}_{0}=\frac{(\beta-n) F_{0}+Y-G}{1+\psi(\overline{\mathcal{v}})}$, and real money balances are given by $\frac{M}{P} s s=$ $\frac{\bar{C}_{0}}{\bar{v}} e^{\gamma t}$. seigniorage is given by $(\bar{\pi}+\gamma+n) \frac{\bar{C}_{0}}{\bar{v}} e^{(\gamma+n) t}$ and its present discounted value is given by $(\bar{\pi}+\gamma+n) \frac{\bar{C}_{0}}{\bar{v}(\beta-n)}$.

\section{VI.2. Central bank's solvency, accounting, and the rule for remittances.}

For some of the papers discussed in the introduction the issue of central bank's solvency is simply not taken into consideration: the worst that can happen is that the fiscal authority may face an uneven path of remittances, with possibly no remittances at all for an extended period. We acknowledge the possibility that remittances may have to be negative, at least at some point, if the central bank wants to continue following the interest rate rule: persisting with its policy rule is impossible without fiscal support from the Treasury. This is what we mean by "insolvency" for a central bank. It is important to keep in mind that this notion of solvency depends on what policy rule the central bank is trying to implement.

Like Reis (2013) and Bassetto and Messer (2013a), we approach the issue of central bank's solvency from a present discounted value perspective. If the left hand side of equation (24) is negative, the central bank cannot face 
its obligations, i.e., pay back reserves, without the support of the fiscal authority. An interesting aspect of equation (24) is that its left hand side does not depend on many of aspects of central bank policy that are recurrent in debates about the fiscal consequences of central bank's balance sheet policy. For instance, the future path of $B_{t}^{C}$ does not enter this equation: whether the central bank holds its assets to maturity or not, for instance, is irrelevant from an expected present value perspective. Intuitively, the current price $q_{t}$ contains all relevant information about the future income from the asset relative to the opportunity cost $r_{t}$. Whether the central bank decides to sell the assets and realize gains or losses, or keep the assets in its portfolio and finance it via reserves, does not matter. Similarly, whether the central bank incurs negative income in any given period, and accumulates a "deferred asset", is irrelevant from the perspective of the overall present discounted value of resources transferred to the fiscal authority. ${ }^{8}$ In fact, scenarios associated with higher remittances in terms of present value may well be associated with a deferred asset.

Finally, in perfect foresight the central bank can always choose a perfectly smooth path of remittances (in fact, this is $\tau_{t}^{C}=\bar{\tau}^{C} e^{\gamma t}$ ). But there are accounting rules governing central banks' remittances. Hence these may not be smooth and may depend on the central bank's actions, such as holding the assets to maturity or not. We recognize that the timing of remittances can matter for a variety of reasons: tax smoothing, political pressures on the central bank, et cetera. We assume a specific rule for remittances that very loosely matches those adopted by actual central banks and compute simulated paths of remittances under different assumptions. Since the rule for

\footnotetext{
${ }^{8}$ As we will see later central bank accounting does not let negative income affect capital. The budget constraint (23) implies however that negative income results in either more liabilities or less assets. To maintain capital nonetheless intact, a "deferred asset" is created on the asset side of the balance sheet.
} 
remittances is not central to our analysis, we leave this discussion to the appendix.

The rule governing future remittances, for a given amount of central bank liabilities, does not matter for our results. This is not to say that the rule for remittances is irrelevant for our discussion of central bank solvency: the amount of past remittances determines the current level of central bank's liabilities, which enter equation (24). Goodfriend (2014) argues that central banks with large, long-duration balance sheets should retain part of their income in order to build a capital buffer. Such a buffer would be purposeless if there were explicit fiscal support via an agreement that central bank capital gains and losses go directly onto the Treasury's balance sheet ${ }^{9}$. But in the absence of such an agreement, a capital buffer could be useful in preserving central bank independence. Of course time inconsistency of political commitments could undermine either a capital buffer or an explicit agreement that capital gains and losses go directly to the treasury's balance sheet. A capital buffer could become a political target if perceived as unnecessarily large; an explicit agreement might work well while capital gains were flowing to the treasury, but be called into question when it started requiring flows in the reverse direction.

VI.3. Functional forms and parameters. Table 3 shows the model parameters. We normalize $Y-g$ to be equal to 1 , and set $F_{0}$ to $0 .{ }^{10}$ Since we do not have investment in our model, and $F_{0}=0, Y-G$ in the model corresponds to national income $Y$ minus government spending $G$ in the data (data are from Haver analytics, mnemonics are Y@USNA and G@USNA, respectively).

\footnotetext{
${ }^{9}$ The Bank of England has such an accounting arrangement with the Treasury (McLaren and Smith, 2013).

${ }^{10}$ Note from the steady state calculations that we could choose $F_{0} \neq 0$ and use instead the normalization $(\beta-n) F_{0}+y-g=1$, hence setting $F_{0} \neq 0$ simply implies a different normalization.
} 
All real quantities discussed in the remainder of the paper should therefore be understood as multiples of $Y-G$, and their data counterparts are going to be expressed as a fraction of national income minus government spending ( $\$ 11492 \mathrm{bn}$ in 2013Q3). Our $t=0$ corresponds to the beginning of 2014. We therefore measure our starting values for the face value of central bank assets $\frac{B^{C}}{P}$, reserves $\frac{V}{P}$, and currency $\frac{M}{P}$ using the January 2, 2014 H.4.1 report (http://www. federalreserve.gov/releases/h41/), which measures the Security Open Market Account (SOMA) assets. ${ }^{11}$ We choose $\chi-$ the average coupon on the central bank's assets - to be 3.4 percent, roughly in line with the numbers reported in figure 6 of Carpenter, Ihrig, Klee, Quinn, and Boote (2013). Chart 17 of the April 2013 FRBNY report on "Domestic Open Market Operations during 2013"12 shows an average duration of 6.8 years for SOMA assets (SOMA is the System Open Market Account, which represents the vast majority of the Federal Reserve balance sheet). Accordingly we set $1 / \delta=6.8$.

\footnotetext{
${ }^{11}$ The January 2, 2014, H.4.1 reports the face value of Treasury (\$2208.791 bn ), GSE debt securities (\$ 57.221 bn), and Federal Agency and GSE MBS (\$ 1490.160 bn), implying that $B_{0}^{C}$ is $\$ 3756.172 \mathrm{bn}$, the value of reserves and other interest-bearing central bank liabilities $V$ (these include reserve balances for $\$ 2374.633$ bn and reverse repurchase agreements for \$ 235.086 bn) and currency $M$ (Federal Reserve currency in circulation \$ 1240.499 bn) on January 1,2014 . Note that while our description of the central bank's balance sheet is coarse, we are not missing any quantitatively important item. Our measure of $B$ includes the totality of "Securities held outright". We are missing "Unamortized premiums / discounts," but that is an accounting measure of $q B-B$, so it is appropriate not to include this item. We are also missing discount window and other credit, gold, foreign currency denominated assets, and Treasury currency on the asset side. Relative to the overall size of the balance sheet, these items are quite small. On the liability side we are missing Treasury cash holdings, "deposits with F.R. Banks, other than reserve balances," which is mostly comprised of the U.S. Treasury general account and other non-interest bearing liabilities. "Term deposits held by depository institutions" are interest bearing and ought to be included in $V$, but were zero on January 1, 2014.

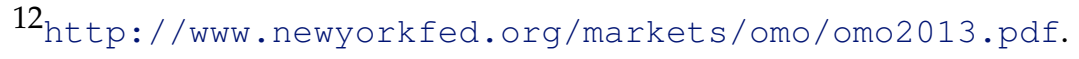


The remaining model parameters are chosen as follows. The discount rate $\beta$, productivity growth $\gamma$, and population growth $n$ are 1 percent, 1 percent, and .75 percent, respectively. These values are consistent with Carpenter et al.'s assumptions of a $2 \%$ steady state real rate.

The policy rule has inflation and interest rate smoothing coefficients $\theta_{\pi}$ and $\theta_{r}$ of 2 and 1 , respectively, which are roughly consistent with those of interest feedback rules in estimated DSGE models (e.g., Del Negro, Schorfheide, Smets, and Wouters (2007); note that $\theta_{r}=1$ corresponds to an interest rate smoothing coefficient of .78 for a policy rule estimated with quarterly data). The inflation target $\theta_{\pi}$ is 2 percent. As in the simple model, we use for transactions costs the functional form (20), which we repeat here for convenience:

$$
\psi(v)=\psi_{0} e^{-\psi_{1} / v}
$$

This transaction cost function implies that the elasticity of money demand goes to zero for very low interest rates, consistently with the evidence in Mulligan and Sala-i Martin (2000) and Alvarez and Lippi (2009). The coefficients $\psi_{0}$ and $\psi_{1}$ used in the baseline calibration are $\psi_{0}=.63$ and $\psi_{1}=$ 103.14. These were obtained from an OLS regression of $\log r$ on inverse velocity, which is justified by the fact that under this functional form for the transaction costs the equilibrium condition (12) implies

$$
\log r=\log \left(\psi_{0} \psi_{1}\right)-\psi_{1} v^{-1}
$$

The left panel of Figure 1 shows the scatter plot of quarterly $\frac{M}{P C}=v^{-1}$ and the annualized 3-month TBill rate in the data (where $M$ is currency and $P C$ is measured by nominal PCE $)^{13}$, where black crosses are post-1959 data,

\footnotetext{
${ }^{13}$ Data are from Haver, with mnemonics C@USNA, FMCN@USECON, and FTBS3@USECON for PCE, currency, and the Tbill rate, respectively.
} 
FiguRE 1. Money Demand and the Laffer Curve Short term interest rates and M/PC
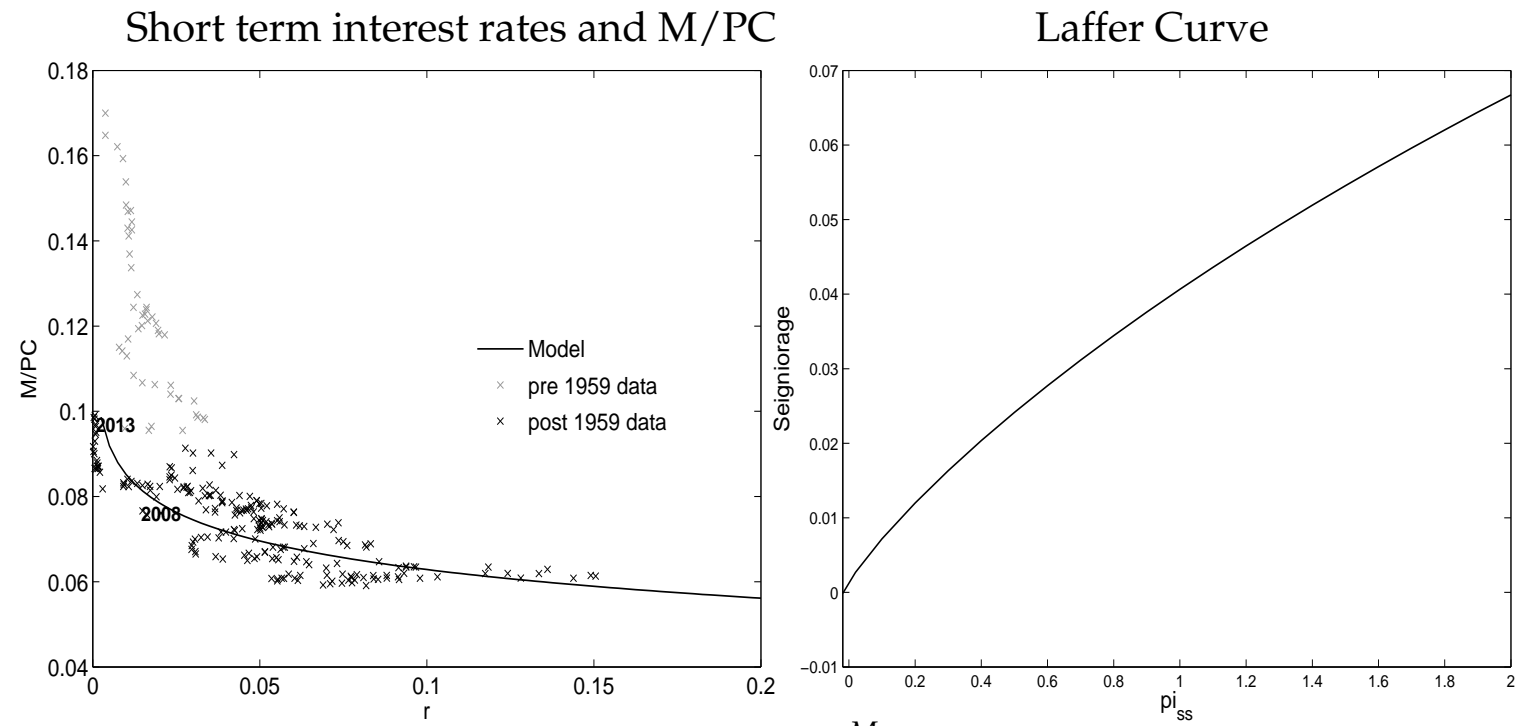

Notes: The left panel shows a scatter plot of quarterly $\frac{M}{P C}=v^{-1}$ and the annualized 3-month TBill rate (black crosses are post-1959 data, and gray crosses are 1947-1959 data) together with relationship between inverse velocity and the level of interest rates implied by the model (solid black line). The right panel shows seigniorage as a function of steady state inflation.

and gray crosses are 1947-1959 data, which we exclude from the estimation as they represent an earlier low-interest rate period where the transaction technology was arguably quite different. The solid black curve in the left panel of Figure 1 shows the relationship between inverse velocity and the level of interest rates implied by the model. ${ }^{14}$ The right panel of Figure 1 shows the steady state Laffer curve as a function of inflation. The figure shows that under our parameterization seigniorage is still increasing even for inflation rates of 200 percent (eventually money demand and seigniorage go to zero, but this only occurs for interest rates above 6500 percent). We also consider alternative parameterizations of currency demand. Specifically, we run the OLS regression excluding post-2008 data and obtain a substantially lower estimate of $\psi_{1}$, implying a greater sensitivity of money demand to interest rates $\left(\psi_{1}=48.17, \psi_{0}=.03\right)$. Figure A-1 in the appendix

\footnotetext{
${ }^{14}$ The implied transaction costs at steady state are negligible - about .04 percent of Y-G.
} 
shows that the Laffer curve under this parameterization appears very different from that in Figure 1, with the Laffer curve peaking at 50 percent interest rates, and money demand going to zero for $r$ above 150 percent. As we discuss later, our quantitative results do not change much depending on which parameterization of the currency demand function we use. Nonetheless, we acknowledge there is much uncertainty regarding future currency demand as new technologies and alternative means of payments (e.g., interest-bearing cash cards) may change it substantially. This implies that much uncertainty surrounds our quantitative findings.

\section{TABLE 3. Parameters}

normalization, foreign assets

$Y-G=1$

$F 0=0$

initial assets, reserves, and currency

$\frac{B^{C}}{P}=0.323 \quad \frac{V}{P}=0.224$

$\frac{M}{P} \quad=0.107$

bonds: duration and coupon

$\delta^{-1}=6.8$

$\chi=0.034$

discount rate, reversion to st.st., population and productivity growth

$\beta=0.01$

$\gamma=0.01$

$\varphi_{1} \quad=0.750$

$\mathrm{n}=0.0075$

monetary policy

$\theta_{\pi}=2 \quad \theta_{r}=1$

$\bar{\pi} \quad=0.02$

money demand

$\psi_{0}=0.63 \quad \psi_{1}=103.14$ 


\section{Simulations}

As a baseline simulation we choose a time-varying path of short term nominal interest rates that roughly corresponds to the baseline interest path in Carpenter, Ihrig, Klee, Quinn, and Boote (2013). We generate this path by assuming that the real rate $\rho_{t}$ remains at a low level $\rho_{0}$ for a period of time $T_{0}$ equal to five years, and then reverts to the steady state $\bar{\rho}$ at the rate $\varphi_{1}$ :

$$
\rho_{t}=\left\{\begin{array}{l}
\rho_{0}, \text { for } t \in\left[0, T_{0}\right] \\
\bar{\rho}+\left(\rho_{0}-\bar{\rho}\right) e^{-\varphi_{1}\left(t-T_{0}\right)}, \text { for } t>T_{0} .
\end{array}\right.
$$

Given the path for $\rho_{t}$, equation (15) generates the path for the nominal short term rate (we set $\kappa=0$ for the baseline simulation). The baseline paths of $\rho_{t}, r_{t}$ and inflation $\pi_{t}$ are shown as the solid black lines in the three panels of Figure 2.

FIGURE 2. Short term interest rates: baseline vs higher rates

Nominal

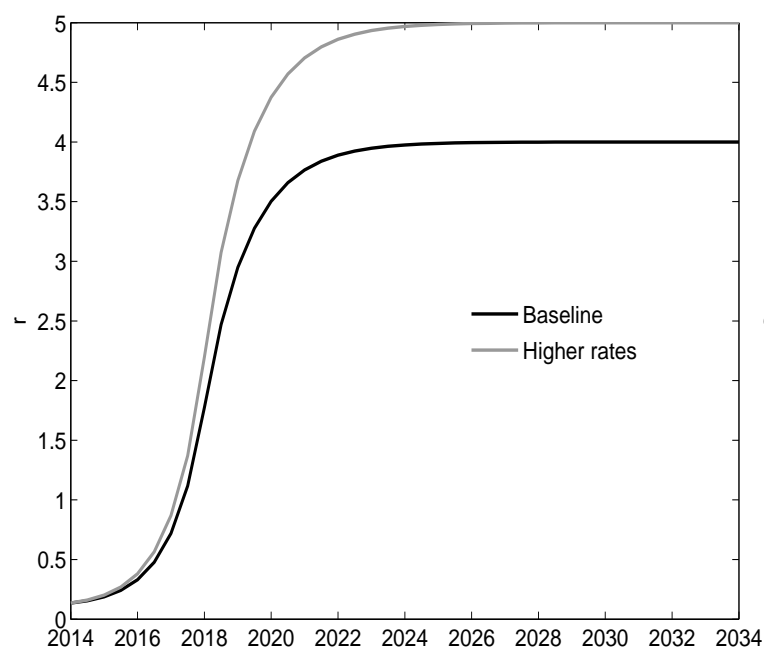

Real

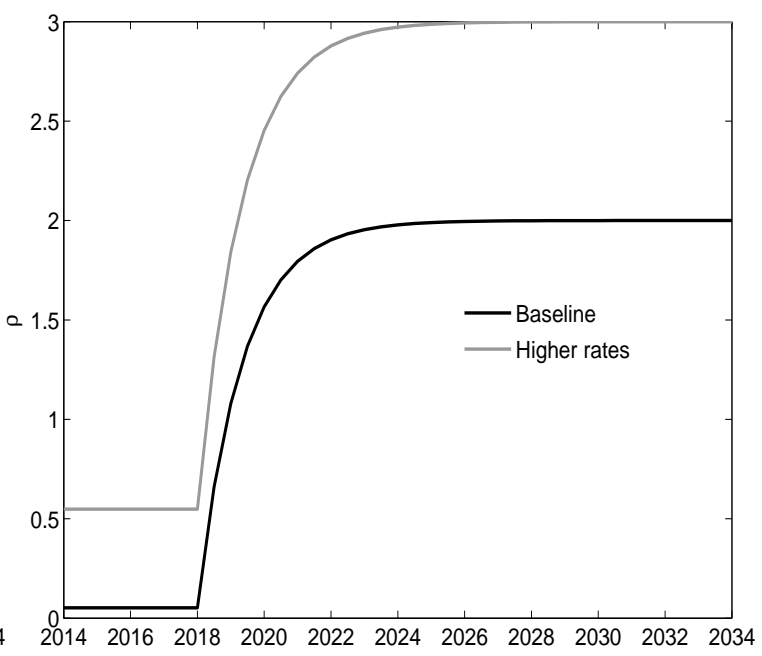

Notes: The panels show the projected path of nominal (left panel) and real (right panel) short term rates under the baseline (solid black) and the "higher rates" (solid gray) scenarios.

Given the path for $\rho_{t}$ and $r_{t}$ we can compute $q$ and the amount of resources, both in terms of marketable assets and present value of future seigniorage, in the hands of the central bank. The first row of table 4 shows 
the two components of the left hand side of equation (24), namely the market value of assets minus reserves (column 1) and the discounted present value of seigniorage $\int_{0}^{\infty}\left(\frac{\dot{M}}{M}+n\right) \frac{M}{P} e^{\int_{0}^{t}\left(\rho_{s}+x_{s}-n\right) d s} d t$ (column 2). The third column shows the sum of the two, which has to equal the discounted present value of remittances $\int_{0}^{\infty} \tau^{C} e^{\int_{0}^{t}\left(\rho_{s}+x_{s}-n\right) d s} d t$. Last, in order to provide information about how the numbers in column 1 are constructed, column 4 shows the nominal price of long term bonds $q$ at time 0 .

TABLE 4. Central bank's resources under different simulations

(3)

(4)

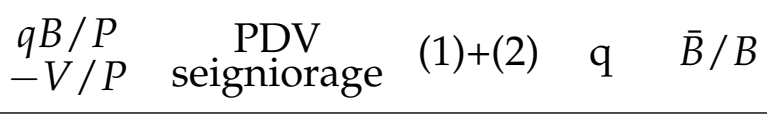

\section{Baseline calibration}

$\begin{array}{lllllll}\text { (1) } & \text { Baseline scenario } & 0.126 & 1.139 & 1.264 & 1.08 & \\ \text { (2) } & \text { Higher rates }(\beta) & 0.109 & 0.181 & 0.291 & 1.06 & 11.86 \\ \text { (3) } & \text { Higher rates }(\gamma) & 0.121 & 1.443 & 1.564 & 1.06 & 59.47 \\ \text { (4) } & \text { Inflation scare } & 0.009 & 0.692 & 0.701 & 0.85 & 4.06 \\ \text { (5) } & \text { Explosive path } & 0.049 & 0.466 & 0.515 & 0.85 & 3.19\end{array}$

$$
\text { Higher } \theta_{\pi}
$$

(6) Inflation scare $\quad 0.028 \quad 0.599 \quad 0.627 \quad 0.90 \quad 4.43$

(7) Explosive path $\quad-0.030 \quad 0.175 \quad 0.145 \quad 0.61 \quad 1.30$

$$
\text { Lower } \theta_{\pi}
$$

(8) Inflation scar

$-0.085$

0.861

$\begin{array}{lll}0.775 & 0.47 & 2.66\end{array}$

(9) Explosive path

0.115

6.806

$\begin{array}{lll}6.922 & 1.05 & 198.83\end{array}$

Notes: The table shows the two components of the left hand side of equation (24), namely the market value of assets minus reserves (column 1) and the discounted present value of seigniorage (column 2). Column 3 shows the sum of the two, which has to equal the discounted present value of remittances. Column 4 shows the nominal price of long term bonds $q$ at time 0 . Column 5 reports for each scenario the level of the balance sheet $\bar{B}^{C}$ (expressed as a fraction of the end-of-2013 level) such that, for any balance sheet size larger than $\bar{B}^{C}$, the present discounted value of remittances becomes negative after the shock. 
Under the baseline simulation the real value of the central bank's assets minus liabilities is 12.6 percent of $Y-G$ - which is larger than the difference between the par value of assets minus reserves reported in table 3 given that $q$ is above one under the baseline. Its value is 1.08 , which is above the 1.04 ratio of market over par value of assets reported in Federal Reserve System (2014). ${ }^{15}$ The discounted present value of seigniorage is almost an order of magnitude larger, however, at 114 percent of $\mathrm{Y}-\mathrm{G}$, and represents the bulk of the central bank resources (and therefore of the present discounted value of remittances), which are 126 percent of Y-G. ${ }^{16}$

Note that our estimate of the present discounted value of seigniorage is quite large. A look at the steady state formula for the PDV of seigniorage provided in section VI explains why this is the case. The numerator in that formula - the flow of seigniorage - is $(\bar{\pi}+\gamma+n) \bar{m}$, where $\bar{m}$ is real money balances. Our calibration implies that this flow is .0027 of $Y-G$, lower than the historical average seigniorage (.0047). The reason why our present discounted value is so large is that the denominator $\beta-n$ is very small. This also implies that the present discounted value numbers are very sensitive to the calibration of the discount rate, as we show below.

The left and right panels of Figures 3 show inverse velocity M/PC and seigniorage, expressed as a fraction of $\mathrm{Y}-\mathrm{G}$, in the data (1980-2013) and in

\footnotetext{
${ }^{15}$ Page 23 and 29 shows the par and market (fair) value of Treasury and GSE debt securities, and Federal Agency and GSE MBS, respectively.

${ }^{16}$ Column 4 in Table A-1 in the appendix shows $\bar{\tau}^{C}$ as defined in equation (25): the constant level of remittances (accounting for the trend in productivity) that would satisfy equation (24), expressed as a fraction of $Y-G$ like all other real variables. That is, the amount $\bar{\tau}^{C}$ such that $\tau_{t}^{C}=\bar{\tau}^{C} e^{\gamma t}$ satisfies the present value relationship. We find that the constant (in productivity units) level of remittances $\bar{\tau}^{C}$ that satisfies the present value relationship is .29 percent of Y-G, about $\$ 34$ bn per year, considerably lower than the amount remitted for 2013 and 2012 according to Federal Reserve System (2014) (\$ 79.6 and \$ 88.4 bn, respectively).
} 
FIGURE 3. seigniorage and M/PC

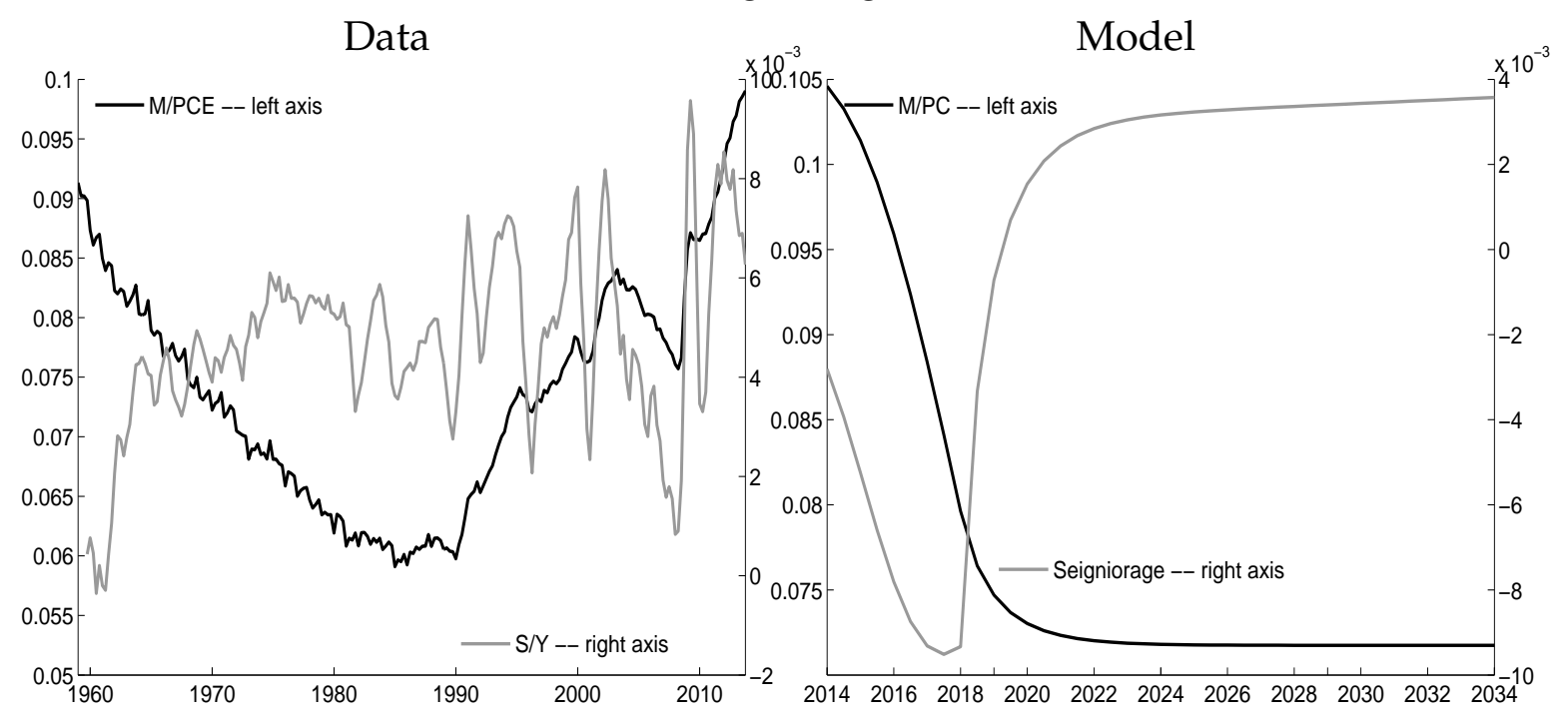

Notes: Paths for seigniorage (solid gray - right axis) and real money balances (solid black - left axis) in the data (left panel) and under the baseline simulation (right panel).

the model (under the baseline simulation), respectively. A comparison of the two figures shows that the drop in $\mathrm{M} / \mathrm{PC}$ as interest rates renormalize under the baseline simulation (from about .09 to .07 , left axis) is roughly as large as the rise in M/PC as interest rates fell from 2008 to 2013. Partly because the model may likely over-predict the fall in currency demand, and more importantly because consumption declines (real interest rates are very low at time 0 , inducing unrealistic above trend consumption), seigniorage falls to negative territory for roughly six years. After that, it converges to almost .3 percent of Y-G, a level that is in the low range of the post-1980 observations. For both reasons the numerator in the present discounted value of seigniorage reported in Table 4 for the baseline simulation is likely to be a fairly conservative estimate. ${ }^{17}$ Table A-2 in the appendix shows the same

${ }^{17}$ The left panel of Figure A-3 in the appendix shows remittances (computed as described in section B) under two scenarios for the path of assets $B^{C}$ : in the first scenario (solid line) the central bank lets its assets depreciate, while in the second one it actively sells assets at a rate of 20 percent per year. These scenarios are both obviously unrealistic, since we know that the size of the balance sheet increased since the end of 2013, but 
quantities of Table 4 obtained under the alternative calibration of money demand. We see that in spite of the differences in the elasticity, the results in terms of central bank's resources are very similar.

Next, we consider alternative simulations where the economy is subject to different "shocks." In each of these simulations all uncertainty is revealed at time 0 , at which point the private sector will change its consumption and portfolio decisions and prices will adjust. We will use the subscript $0^{-}$to refer to the pre-shock quantities and prices (that is, the time 0 quantities and prices under the baseline simulation). For each simulation, Table 4 will report the new market value of assets minus reserves in real term $\left(q_{0} \frac{B_{0^{-}}^{C}}{P_{0}}-\frac{V_{0}}{P_{0}}\right)$. By assumption the central bank will not change its assets $B_{0^{-}}^{C}$ after the new information is revealed, but the private sector will change its time 0 currency holdings given that interest rates may have changed. This necessarily leads to a change in reserves (given that central bank's assets are unchanged) equal to

$$
\frac{V_{0}-V_{0^{-}}}{P_{0}}=-\frac{M_{0}-M_{0^{-}}}{P_{0}},
$$

in real terms (we report this quantity in column 6 of Table A- 1 in the appendix).

For each scenario we also report the level of the balance sheet $\bar{B}^{C}$ such that, for any balance sheet size larger than $\bar{B}^{C}$, the present discounted value of remittances (see equation (24)) becomes negative after the shock. We refer to this situation as the central bank becoming "insolvent", in the sense that it needs resources from the fiscal authority because it suffered losses due to the fall in $q$. Specifically, assume the central bank expands its balance sheet by $\Delta B^{C}$ at time $0^{-}$(right before the shock takes place) by buying assets at highlight the fact that different paths for the balance sheet can imply different paths for remittances, even though their expected present value remains the same (this is the dotted line in Figure A-3, which shows $\bar{\tau}^{C} e^{\gamma t}$ ). 
price $q_{0^{-}}$and pays for its purchases by expanding reserves by an amount $\Delta V=q_{0^{-}} \Delta B^{C}$. How large can $\Delta B^{C}$ be to still satisfy

$$
\begin{aligned}
& \frac{q_{0}\left(B^{C}+\Delta B^{C}\right)-V-\Delta V}{P_{0}} \\
& \quad+\frac{M_{0}-M_{0^{-}}}{P_{0}}+\int_{0}^{\infty}\left(\frac{\dot{M}_{t}}{M_{t}}+n\right) \frac{M_{t}}{P_{t}} e^{-\int_{0}^{t}\left(\rho_{s}+x_{s}-n\right) d s} d t \geq 0
\end{aligned}
$$

after the "shock"? Column 5 of Table 4 reports $\bar{B} / B^{C}=1+\frac{\Delta B^{C}}{B^{C}}$, where $B^{C}$ is the 2013Q4 level of the balance sheet reported in Table 3.

The first alternative scenario we study is a "higher rates" path similar to one considered by Carpenter, Ihrig, Klee, Quinn, and Boote (2013). Under this new path real rates converge to a 1 percent higher steady state, and so will short term nominal rates given that the central bank inflation target has not changed. We choose the new starting value for $\rho, \rho_{0}$, so that the initial rate remains at 13.5 basis points. The gray solid lines in the two panels of Figure 2 show the "Higher Rates" paths for the nominal and the real short term rates, respectively. In these simulations we assume that the central bank recognizes the change in the steady state $\bar{\rho}=\beta+\gamma$, and adjusts its Taylor rule coefficient $\bar{r}=\bar{\rho}+\bar{\pi}$ accordingly.

We consider two different reasons why the new steady state $\rho$ is higher: a higher discount rate $\beta$ and a higher growth rate of technology $\gamma$. While the new value of $q$ is the same in both cases (the interest rate path is the same), the present value of seigniorage shown in column 2, and therefore the present value of remittances shown in column 3 , is quite different. In the high $\beta$ case the current value of the future income from seigniorage falls by almost one order of magnitude, as future seigniorage is discounted at a higher real rate. In the high $\gamma$ case the economy is growing faster, and so does money demand and future seigniorage. Table A- 1 in the appendix shows that in both cases (higher $\beta$ and higher $\gamma$ ) the level of $\bar{\tau}^{C}$ is higher than in the baseline case. Carpenter, Ihrig, Klee, Quinn, and Boote (2013) 
take seigniorage as given and focus on the effect of the higher nominal interest rates on the value of the central bank's assets $q B^{C}$, which falls following the drop in $q$. The effect of the higher real rate of return on future central bank's revenues and, especially in the high $\gamma$ case, on future seigniorage, trumps in our simulation the negative effect on $q .{ }^{18}$

FIGURE 4. "Inflation scare" and "explosive paths" scenarios: The effect on short terms rates under different inflation responses in interest rate rule
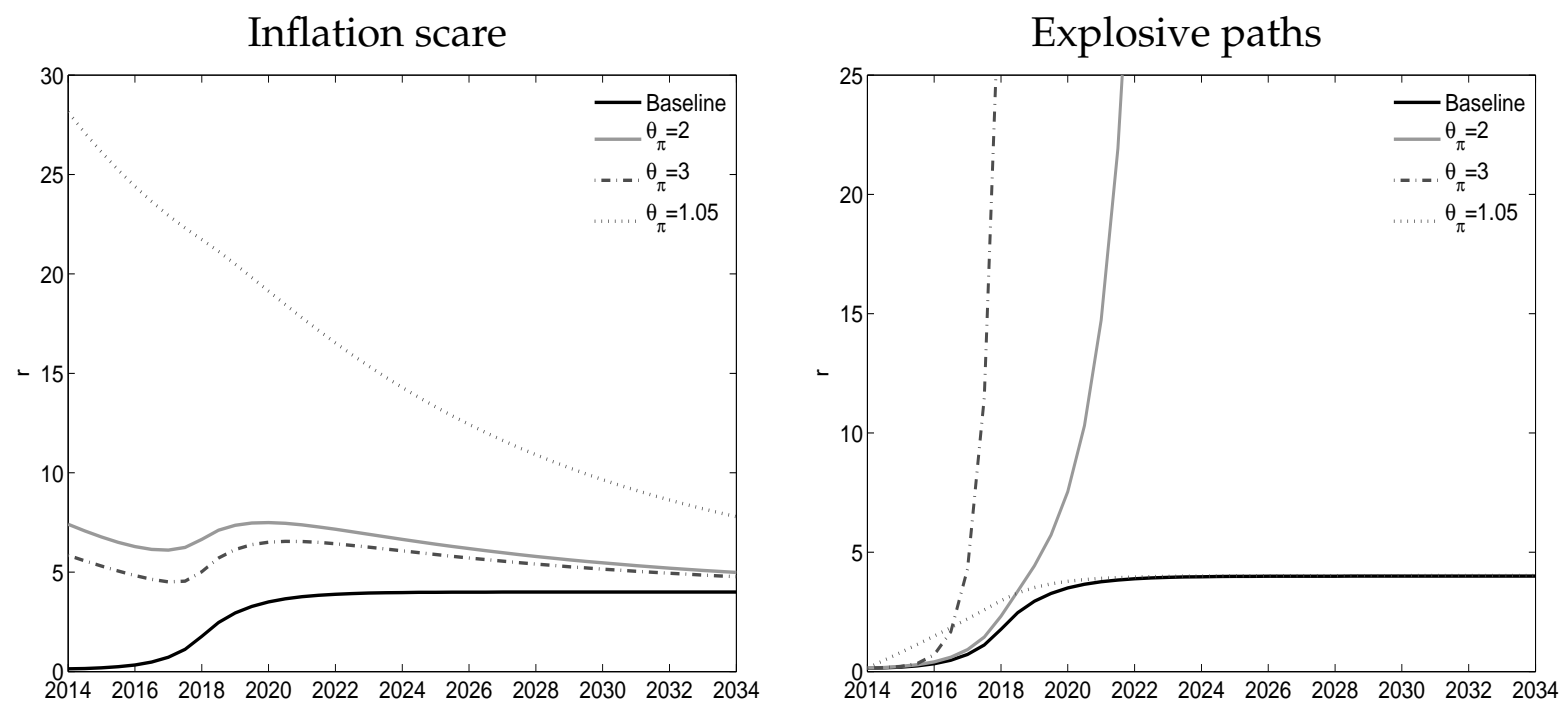

Notes: The panels show the projected path of nominal short term rates for the "inflation scare" (left panel) and the "explosive path" scenario (right panel, with $\kappa=10^{-4}$ ) under different inflation responses in interest rate rule (solid gray: $\theta_{\pi}=2$, dash-and-dotted gray: $\theta_{\pi}=3$; dotted gray: $\theta_{\pi}=1.05$ ) together with the baseline projections (solid black).

Next, we consider simulations where the private sector is concerned about a sudden jump in the price level, and therefore demands a premium $x_{t}$ for holding nominal bonds as described in section II ("inflation scares" scenarios). We assume that this premium follows the process

$$
x_{t}=x_{0} e^{-\chi_{x} t},
$$

\footnotetext{
${ }^{18}$ This may seem surprising in the higher $\beta$ case since the present value of seigniorage is lower than under the baseline simulation. However, the central bank is now earning a higher return on its assets, and can therefore afford a higher level of remittances.
} 
with $x_{0}=.04$ and $\chi_{x}=.1$. The solid gray line in the left panel of Figure 4 shows the path of the short term nominal interest rates under this scenario, which is higher than under the baseline because the higher inflation expectations force the central bank to raise rates (the corresponding paths for inflation are shown in Figure A- 4 in the appendix). Row 4 of Table 4 shows the effects of this scenario on the central bank's balance sheet. The market value of assets minus reserves $q_{0} \frac{B_{0^{-}}^{C}}{P_{0}}-\frac{V_{0}}{P_{0}}$ drops to almost zero, both because $q$ falls and because a higher fraction of the central bank's liabilities becomes interest bearing relative to the baseline scenario. This happens because the private sector turns currency into reserves, driven by the higher opportunity cost of holding currency. Under our assumptions on money demand, the present discounted value of seigniorage, while lower than in the baseline case, is still sizable, and so is the present value of resources in the hands of the central bank under this scenario. As a consequence, even with a much larger balances sheet (more than four times as large) the central bank could have withstood the fall in the value of its assets without ever needing any resources from Fiscal Authority. Table A-2 in the appendix shows that these results are robust to the parameterization of money demand.

The quantitative results are sensitive to the inflation response in the policy reaction function. The dash-and-dotted and dotted gray lines in the left panel of Figure 4 show the interest rate path corresponding to an inflation coefficient $\theta_{\pi}$ of 3 and 1.05 , respectively. ${ }^{19}$ As is usually the case in stable rational expectations equilibria, a higher inflation coefficient in the interest rate rule induces a lower equilibrium response of inflation, and therefore a lower equilibrium response of interest rates - and vice versa when the inflation response is lower. When $\theta_{\pi}$ is 1.05 , interest rates reach almost 30

\footnotetext{
${ }^{19}$ In these simulations we change the time 0 real rate so that under the baseline scenario the nominal rate is still 13.5 basis points.
} 
percent. Consequently, $q$ falls to less than half its value in the baseline scenario, and the market value of assets minus reserves $q_{0} \frac{B_{0^{-}}^{C}}{P_{0}}-\frac{V_{0}}{P_{0}}$ falls to negative levels (see row 8 of Table 4). The implication of this finding is that under a large balance sheet the central bank may want to respond more aggressively to inflation if it is concerned about fluctuations in the values of its assets.

Even in the $\theta_{\pi}=1.05$ case central bank's solvency is not an issue, however. The central bank's overall resources (column 3) are still sizable, because the higher inflation experienced under the lower $\theta_{\pi}$ policy yields greater seigniorage (column 2). In fact, the present value of remittances would remain positive even if we assumed the central bank balance sheet to be more than twice as large as the current one (column 5).

Finally, we consider explosive paths where $\kappa$ in equation (15) is different from zero. The solid gray line in the bottom right panel of Figure 4 shows one of these paths (with $\kappa=10^{-4}$ ) under the baseline policy response. Given the rise in $r_{t}$ under this scenario, $q$ drops substantially relative to the baseline (row 5 of Table 4). The present discounted value of seigniorage also falls relative to the baseline because seigniorage goes to zero as rates become larger than 6500 percent. But it is still large enough that even with a balance sheet more than three times as large as $B_{0}^{c}$ the central bank would be solvent. This is one case where using the alternative parameterization of money demand makes a difference, however. Table A-2 in the appendix shows that under explosive paths the central bank would not be solvent under the current size of the balance sheet, which is not surprising since under this parameterization the peak of the Laffer curve is crossed at interest rates around 50 percent.

The dash-and-dotted and dotted gray lines in the bottom right panel of Figure 4 show the responses under different $\theta_{\pi}$ coefficients. In the case of unstable solutions, the inflation response coefficient in the interest rule 
plays the opposite role relative to the stable solution case (see Cochrane (2011)): the stronger the response, the faster inflation and interest rates explode. The market value of central bank's assets $q$ surely falls more with a higher $\theta_{\pi}$, and indeed $q_{0} \frac{B_{0^{-}}^{C}}{P_{0}}-\frac{V_{0}}{P_{0}}$ falls to negative levels. The present discounted value of seigniorage also falls by more than in the $\theta_{\pi}=2$ case, but not by enough to call central bank's solvency in question under these paths.

\section{SELF-FULFILLING SOLVENCY CRISES}

As we have already observed, a central bank cannot guarantee determinacy of the price level in the absence of fiscal backing. Our detailed scenarios in the previous sections have all assumed (except in the $\mathcal{K}>0$ cases) that this backing was present. But even when the backing is present, a central bank that is firmly committed to not accepting (or incapable of drawing on) fiscal support, in the sense of capital injections from the treasury, can create indeterminacy in the price level.

What if the public believes that, were the central bank to face the issue of solvency, it would resort to seigniorage creation? Entertaining this possibility would then lead the public to expect higher future inflation and nominal interest rates. These expectations would result in a lower value of long term nominal assets today, so that the central bank's assets $q B^{C}$ could become worth less than its interest bearing liabilities $V$. If the current present discounted value of seigniorage is not large enough to cover this gap, the central bank might have to resort to raising more seigniorage, thereby validating the initial belief. The larger is the size of the central bank's balance sheet, and the longer its duration, the larger is the gap in $q B^{C}-V$ that would arise 
because of future expected inflation, and the higher the likelihood of these alternative equilibria. ${ }^{20}$

We make this point more formally by focusing on a simple setting. We assume that the central bank chooses at time 0 the inflation target $\bar{\pi}$ in its Taylor rule (5) and would like to set it to 2 percent. In choosing $\bar{\pi}$, we assume that the central bank is constrained by the lack of fiscal support hence $\tau_{t}^{C} \geq 0$ in all future periods $t \geq 0$, implying that the left hand side of the intertemporal constraint (24) must be non-negative for all $t \geq 0$ - and by the equilibrium conditions (11), (12), (24), (29), (30), (32), (33).

We have already verified that if the central bank chooses a target of 2 percent for all periods $\left(\bar{\pi}_{t}=.02\right)$ and the public's expectations align with this choice, the central bank solvency constraint is slack (see Table 1). This is therefore an equilibrium, as it satisfies the central bank's objective and all the constraints. But there may be other equilibria where the public instead believes that the central bank will be forced by balance sheet considerations to push inflation, and thus seigniorage, higher. In these equilibria the level of $\bar{\pi}$ is $\tilde{\pi}>.02$ and the solvency constraint is satisfied:

$$
\frac{q_{0}(\tilde{\pi}) B_{0^{-}}^{C}-V_{0}(\tilde{\pi})}{P_{0}(\tilde{\pi})}+P D V S_{0}(\tilde{\pi}) \geq 0,
$$

\footnotetext{
${ }^{20}$ There is a connection between self-fulfilling equilibria in this paper and the literature on currency crisis (e.g., Burnside, Eichenbaum, and Rebelo (2004)) and debt crisis (especially Calvo (1988)). In Burnside, Eichenbaum, and Rebelo (2004), government guarantees lead to the possibility of self- fulfilling speculative attack on the exchange rate regime. In this paper, the presence of long-duration assets in the central bank's balance sheet makes it vulnerable to expectations of higher future inflation, and the lack of fiscal support makes these expectations self-fulfilling because it has to resort to seigniorage. Similarly, a large, long-duration balance sheet in this model plays the same role as a large outstanding amount of debt in Calvo, in that it "may generate the seeds of indeterminacy; it may, in other words, generate a situation in which the effects of policy are at the mercy of people's expectations ... "(Calvo (1988), pg. 648).
} 
where $q_{0}(\tilde{\pi}), P_{0}(\tilde{\pi}), V_{0}(\tilde{\pi})$, and $P D V S_{0}(\tilde{\pi})=\int_{0}^{\infty}\left(\frac{\dot{M}_{t}}{M_{t}}+n\right) \frac{M_{t}}{P_{t}} e^{-\int_{0}^{t}\left(\rho_{s}-n\right) d s} d t$ are the time 0 asset price, price level, reserves, and present discounted value of seigniorage, respectively, implied by the inflation target $\tilde{\pi}^{21}$ Values of $\tilde{\pi}$ for which equation (39) is satisfied are possible self-fulfilling solvency crises, in the sense that the expectation that the central bank will switch to a new rule with target $\bar{\pi}$ will produce a gap in the value of central bank's assets minus liabilities $\frac{q_{0}(\bar{\pi}) B_{0^{-}}^{C}-V_{0}}{P_{0}(\bar{\pi})}$ that will be filled with future seigniorage $\operatorname{PDVS}_{0}(\bar{\pi})$.

To keep the analysis of the equilibrium simple, suppose that the public expects the central bank to follow a Taylor rule with either $\bar{\pi}=.02$ or $\bar{\pi}=\tilde{\pi}$. If 1 ) condition (39) is satisfied, and 2) with $\bar{\pi}$ at the desired .02 level instead of $\tilde{\pi}$ condition (39) is not satisfied, then there are two possible equilibria. The public may believe the higher value of $\bar{\pi}$ is likely, in which case the central bank must set $\bar{\pi}=\tilde{\pi}$ to avoid the need for a capital injection, as we show in appendix $C$; or the public may believe that the $\bar{\pi}=.02$ equilibrium will prevail, in which case it does. ${ }^{22}$

If the size of the balance sheet $B_{0}^{C}$ is at a level $\bar{B}(\tilde{\pi})$ that makes (39) hold with equality when the public expects a target $\tilde{\pi}$, then the conditions for multiplicity are certainly met. However, even for a slightly smaller size of the balance sheet pursuing a $\bar{\pi}=.02$ policy may not generate enough seigniorage if the public expects $\bar{\pi}=\tilde{\pi}$. This is because the difference between $\operatorname{PDVS}_{0}(\tilde{\pi})$ and the seigniorage generated under the deviation $\bar{\pi}=$

\footnotetext{
${ }^{21}$ As mentioned in the discussion of equation (36), $V_{0}$ differs from the initial level of reserves $V_{0^{-}}$because of time 0 changes in currency demand.

${ }^{22}$ It may seem contradictory to suppose that, if the policy authority sticks to $\bar{\pi}=.02$, expected inflation remains on the higher path. If the public thinks of the higher inflation as being generated by randomly timed neutral jumps in $M$ and $P$ (as in our inflation scare example of Section II), however, there is no clear irrationality in their maintaining high inflation expectations despite low realized inflation.
} 
.02 is large enough to overwhelm the reduction in the gap $V_{0}-q_{0} B_{0}^{C}$ arising from a smaller balance sheet $B_{0}^{C} \cdot{ }^{23}$ Below some level $\underline{B}(\tilde{\pi})$ high inflation expectations are no longer self-fulfilling. The central bank can avoid a capital injection despite the high inflation expectations, even if it maintains $\bar{\pi}=.02$, and the public will have no reason to believe that $\bar{\pi}=\tilde{\pi}$ will be forced by a need to avoid a capital injection.

Whether multiple equilibria are possible depends on the level (and duration) of the balance sheet. The top two panels in Figure 5 show, as a function of $\tilde{\pi}$, the range of initial balance sheet values $(\bar{B}, \underline{B})$ for which multiple equilibria are possible. The left and right panels are for the baseline calibration and for an alternative calibration where the discount rate $\beta$ is 0.02 , respectively. The figure shows that under the baseline money demand calibration, the upper, $\bar{B}$ balance sheet level is in all cases much larger than the end-of-2013 one $(\bar{B} / B>1)$, and also larger than the level of the balance sheet reached on January 292015 (this is \$ 4244 bn, or 13 percent higher than the end-of-2013 level, and is shown by a gray horizontal line). The lower end of the range comes much closer to the January 2015 level of the balance sheet, though, and indeed goes below it for the $\beta=.02$ case at very high $\tilde{\pi}$ levels. At levels of initial balance sheet below $\bar{B}$ but above $\underline{B}$, seigniorage more than covers the initial capital loss, and at the low end of the range, with $B$

\footnotetext{
${ }^{23}$ It is important that we have considered $\tilde{\pi}$ and 2 percent as the only two choices of the central bank. If we allow the central bank to entertain any response $\hat{\pi} \in[.02 \tilde{\pi}]$, then they would choose the lowest $\hat{\pi}$ satisfying condition (39) with equality. We would still have two possible equilibria, but in this case, unless eqrefeq:mul held with equality at $\bar{\pi}=\tilde{\pi}$, the higher-inflation equilibrium would have actual $\bar{\pi}$ below its expected value $\tilde{\pi}$ and would therefore not be a self-confirming equilibrium. A more sophisiticated analysis would credit the public with the ability to learn by observing central bank behavior and credit the central bank with the ability to choose time varying as well as constant paths for $\bar{\pi}$, or even to revert to passive monetary policy. We leave a deeper analysis to future research.
} 


\section{FIGURE 5. Self-fulfilling solvency crises}

\section{Baseline Calibration $\quad \beta=0.02$}

\section{Threshold Balance Sheet Limits}
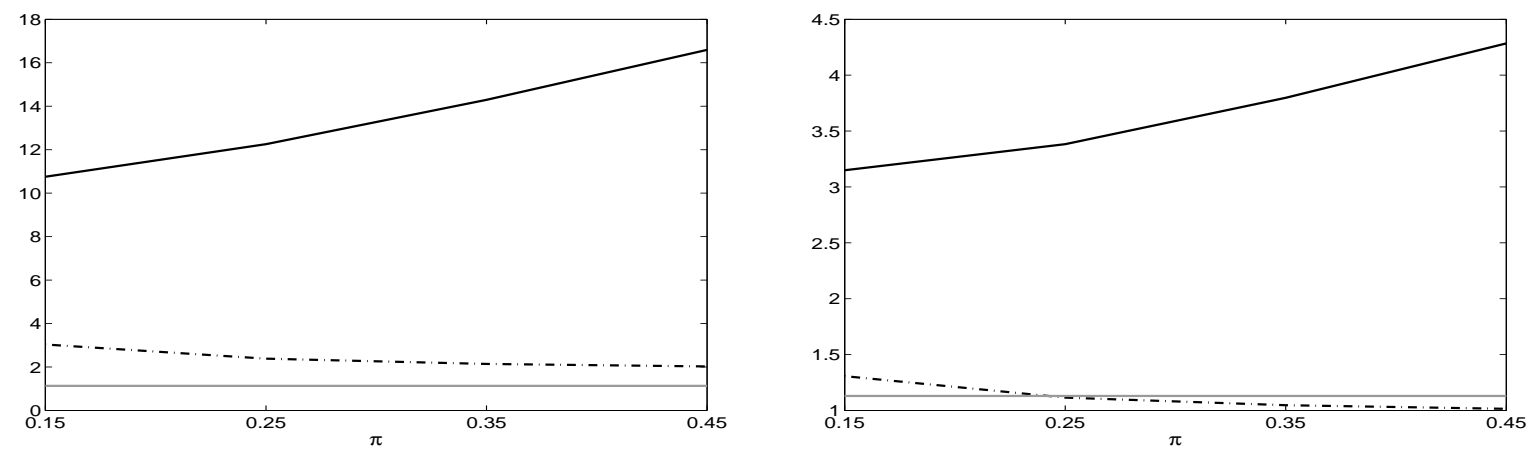

$q B-V$
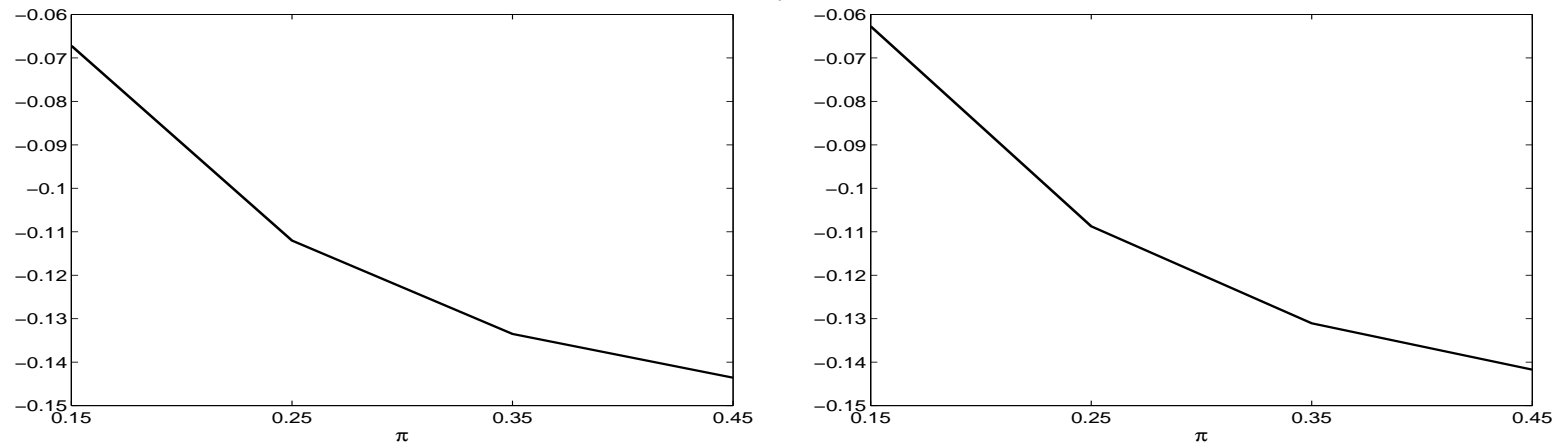

PDV of Seigniorage
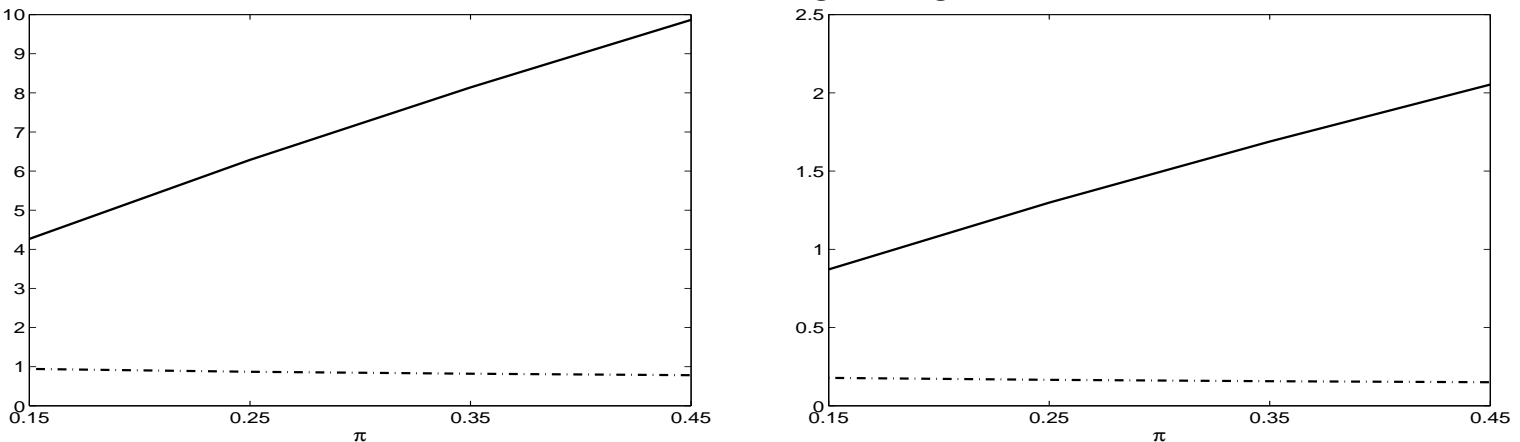

Notes: The figure shows the following quantities as a function of inflation target expected by the public $(\tilde{\pi}): 1$ ) Top panel: the range of the balance sheet levels (relative to the end-of-2013 level reported in Table 3) for which multiple equilibria are possible; black solid and dash-and-dotted lines are the upper $(\bar{B} / B)$ and lower $(\underline{B} / B)$ range, respectively, and the gray horizontal line denotes the level of the balance sheet as of January $292015 ; 2$ ) Middle panel: the level of $q B-V$ as a fraction of income for the current balance sheet size under alternative scenarios; 3 ) Bottom panel: the level of seigniorage as a fraction of income for the case where the central bank validates the public's expectations (solid black line) and where it follows the preferred 0.02 target (dash-and-dotted black line). The left and right columns are for the baseline calibration and for an alternative calibration where the discount rate $\beta$ is 0.02 , respectively. 
just above $\underline{B}$, the seigniorage in the high-inflation equilibrium is so far in excess of what is needed that such equilibria are implausible.

The middle panel shows what happens to $\frac{q_{0}(\tilde{\pi}) B_{0^{-}}^{C}-V_{0}}{P_{0}(\tilde{\pi})}$ in the alternative equilibrium under the current balance sheet size. The baseline case (left) column of the figure shows that for $\tilde{\pi}$ greater than 15 percent the real value of assets minus interest bearing liabilities does become negative. The solid black line in the bottom panel of Figure 5 shows that for these values the level of seigniorage $P D V S_{0}(\tilde{\pi})$ overshadows this balance sheet loss: the increase in seigniorage triggered by the higher inflation regime is larger than the balance sheet loss caused by the fall in $q .{ }^{24}$ Hence the results in the top left panel: the size of the balance sheet would have to be much larger than the current one for the balance sheet loss to be of the same size of the increase in seigniorage.

The middle plot in the right-hand column of the figure shows that with a higher real rate, the initial capital loss in the high-inflation equilibrium is about the same order of magnitude as in the base case. But the bottom right plot shows, via the vertical axis labels, that seigniorage is much lower in this case, which is why we saw in the top right graph that multiple equilibria could occur at the January 2015 level of the balance sheet, at very high levels of inflation and at the lower end of the $(\bar{B}, \underline{B})$ range.

Though this example shows multiple equilibria are in principle possible, it does not generate convincing examples of multiple equilibria at or near current levels of the Fed balance sheet. We should bear in mind, however, that these results are sensitive to parameter values within reasonable ranges, as shown by the contrast between the two columns of Figure 5 . In addition, including features that are absent in this simple model, such

\footnotetext{
${ }^{24}$ The Laffer curve in the right panel of Figure 1 shows why the increase in seigniorage is so large under the baseline parameterization of money demand: even for large interest rates seigniorage grows almost linearly with inflation.
} 
as variations in term premia, could change the quantitative results significantly. ${ }^{25}$

The multiplicity considered in this section can be eliminated with fiscal support for the central bank's balance sheet such as the arrangement between the Bank of England and Her Majesty's Treasury, whereby all gains and losses incurred by the former as part of its asset purchase facility are transfered to the latter (see McLaren and Smith (2013)). In this model, the mere presence of fiscal support eliminates the multiplicity, without any need for actual support in equilibrium.

\section{CONCLUSIONS}

The large balance sheet of many central banks has raised concerns that they could suffer significant losses if interest rates rose, and might need a capital injection from the fiscal authority. This paper constructs a simple deterministic general equilibrium model, calibrated to US data, to study the the impact of alternative interest rates scenarios on the central bank's balance sheet.

One fundamental point that the model illustrates is that concerns about the central bank balance sheet are distinct from concerns about whether fiscal policy is such as to guarantee a determinate price level. The literature on the fiscal theory of the price level studies mutual constraints on fiscal

\footnotetext{
${ }^{25}$ Figure A-5 in the appendix shows that multiple equilibria may rise under the current balance sheet level if expectations about future seigniorage change dramatically relative to the baseline. There, we explore multiple equilibria in the situation where we consider non stationary solutions to equation (15): in these simulations, $\kappa<0$ implies that the interest rate is bound to eventually hit the lower limit $\underline{r}$ and to remain there forever after (in absence of the appropriate fiscal policies alluded to in section III; we choose $\kappa$ so that the ZLB is hit again after 3.5 years). Under many of these paths the present discounted value of seigniorage is no longer enough to compensate for the decline in the value of the central bank assets.
} 
and monetary policy required to guarantee a determinate price level. That kind of fiscal-monetary policy interaction, which we call fiscal "backing", is distinct from the within-government transfers between the treasury and the central bank that are the main focus of this paper, and that we label fiscal "support". Most of our analysis simply assumes fiscal backing, though we do show that the absence of fiscal backing ( $\kappa \neq 0$ solutions) can make a dramatic difference to our simulations and calculations of the need for fiscal support. ${ }^{26}$

Assuming fiscal backing, we show that the central bank's policy rule (or, equivalently, inflation objectives), and the behavior of seigniorage under high inflation are crucial in determining whether a capital injection i.e. fiscal support - might be needed. We show also that a central bank that is seen as ready, in order to avoid a need for capital injection, to create seignorage by altering its inflation objectives, can thereby lose control of the price level, even where with a different policy, or with assured fiscal support, the central bank could control the price level.

Our simulations indicate that for balance sheet levels similar to the current ones of the Federal Reserve system, direct treasury support would be necessary only under what seem rather extreme scenarios. However this result depends on assumptions about demand for non-interest bearing Fed liabilities (mainly currency) that cannot be firmly grounded in empirical estimates. Moreover, our simple model fails to capture several important features, such as changes in risk premia, that would likely change the quantitative results. Higher balance sheet levels, or a lower currency demand than assumed here may force the central bank to request a capital injection in order to maintain its inflation control policy.

\footnotetext{
${ }^{26}$ Since in the absence of fiscal backing the central bank cannot control the price level, these $\kappa \neq 0$ paths, on which the central bank sticks to a policy rule despite being unable to control inflation by doing so, are hypothetical at best, illustrating mainly how important it is that fiscal backing be maintained.
} 


\section{REFERENCES}

AlvareZ, F., AND F. LiPPI (2009): "Financial innovation and the transactions demand for cash," Econometrica, 77(2), 363-402.

BARRo, R. J., AND X. SAla-I MARTIN (2004): Economic Growth. The MIT Press, second edn.

Bassetto, M., and T. Messer (2013a): “Fiscal Consequences of Paying Interest on Reserves," Federal Reserve Bank of Chicago working paper No. 2013-04.

(2013b): “Fiscal consequences of paying interest on reserves," Fiscal Studies, 34(4), 413-436.

Benigno, P., And S. Nisticó (2014): "Monetary Policy Consequences of the Central Bank's Balance Sheet," Discussion paper, LUISS Guido Carli.

Berriel, T. C., And S. Bhattarai (2009): "Monetary Policy and Central Bank Balance Sheet Concerns," The BE Journal of Macroeconomics, 9(1).

Bhattarai, S., G. B. Eggertsson, and B. Gafarov (2013): “Time Consistency and the Duration of Government Debt: A Signalling Theory of Quantitative Easing," mimeo, Brown University.

BUiter, W. H., AND E. RAHBARI (2012): “The ECB as Lender of Last Resort for Sovereigns in the Euro Area," CEPR Discussion Paper No. 8974.

Burnside, C., M. Eichenbaum, and S. Rebelo (2004): “Government guarantees and self-fulfilling speculative attacks," Journal of Economic Theory, 119(1), 31-63.

CAlvo, G. A. (1988): "Servicing the public debt: The role of expectations," The American Economic Review, pp. 647-661.

Carpenter, S. B., J. E. Ihrig, E. C. Klee, D. W. Quinn, and A. H. Bоote (2013): “The Federal Reserve's Balance Sheet and Earnings: A primer and projections," FEDS Working Paper, 2013-01. 
Christensen, J. H. E., J. A. Lopez, and G. D. Rudebusch (2013): “A Probability-Based Stress Test of Federal Reserve Assets and Income," Federal Reserve Bank of San Francisco Working Paper 2013-38.

Cochrane, J. H. (2011): "Determinacy and Identification with Taylor Rules," Journal of Political Economy, 119(3), 565-615.

Corsetti, G., And L. Dedola (2012): “The mystery of the printing press: self-fulfilling debt crises and monetary sovereignty," mimeo Oxford University.

Del Negro, M., F. Schorfheide, F. Smets, and R. Wouters (2007): "On the Fit of New Keynesian Models," Journal of Business and Economic Statistics, 25(2), $123-162$.

Federal Reserve System (2014): “The Federal Reserve Banks. Combined Financial Statements as of and for the Years Ended December 31, 2013 and 2012 and Independent Auditors' Report," http://www. federalreserve.gov/monetarypolicy/files/BSTcombinedfinstmt2013.pdf.

Goodfriend, M. (1993): “Interest Rate Policy and the Inflation Scare Problem," Federal Reserve Bank of Richmond Economic Quarterly, 79(1), 1-23.

_ (2014): "Monetary Policy as a Carry Trade," Institute for Monetary and Economic Studies, Bank of Japan, pp. 29-44.

GreenlaW, D., J. D. Hamilton, P. Hooper, and F. S. Mishkin (2013): "Crunch Time: Fiscal Crises and the Role of Monetary Policy," Manuscript.

HALL, R. E., AND R. ReIS (2013): “Maintaining Central-Bank Solvency under New-Style Central Banking," manuscript.

McLaren, N., And T. Smith (2013): “The Profile of Cash Transfers between the Asset Purchase Facility and Her Majesty's Treasury," Bank of England Quarterly Bulletin, p. Q1.

Mulligan, C. B., AND X. SAla-I MARTin (2000): “Extensive margins and the demand for money at low interest rates," Journal of Political Economy, 108(5), 961-991. 
QuinN, S., AND W. RoberdS (2014): "Death of a Reserve Currency," Atlanta Fed Working Paper 2014-17.

REIS, R. (2013): “The mystique surrounding the central bank's balance sheet, applied to the European crisis," American Economic Review: Papers E Proceedings, 103(3), 135âĂŞ140.

SIMS, C. A. (2005): "Limits to Inflation Targeting," in The Inflation-Targeting Debate, ed. by B. S. Bernanke, and M. Woodford, vol. 32, chap. 7, pp. 283310. NBER Studies in Business Cycles.

Stella, P. (2005a): "Central Bank Financial Strength, Transparency, and Policy Credibility," IMF Staff Papers, 52(2), http: //www. internationalmonetaryfund.org/External/Pubs/FT/staffp/2005/02/stellal.htm.

- (2005b): "Special Section on Central Bank Financial Independence and Policy Credibility:," IMF Staff papers, 52(2), Three papers. Introduction by Stella.

WoOdFord, M. (2001): "Fiscal Requirements for Price Stability," Journal of Money, Credit and Banking,, 33(1), 669-728. 
Appendix A. Plausible Fiscal Rules That Deliver Uniqueness

It is easy to specify a fiscal and monetary policy pair that delivers uniqueness of the price level. For example monetary policy that pegs the interest rate at some fixed level $\bar{r}$ and the primary surplus at some fixed positive level $\bar{\tau}$. With such a combination of policies in the simple model, there is a stable equilibrium with constant inflation (zero inflation if $\bar{r}=\rho$ ). There are unstable solution paths for the model's differential equations, but on these unstable paths the level of real debt $B / P$ grows exponentially upward at the rate $\rho$ or declines in finite time to hit zero, while inflation remains constant. In the former case, the private sector accumulates real wealth in the form of $B / P$ while its consumption remains bounded. This cannot be optimal behavior. It is ruled out by what is called a "transversality condition". It is easy to understand that if the economy started on such a path, private sector agents would try to spend their exploding wealth, pushing the price level up. The resulting inflation would bring the level of real debt back down to the level consistent with equilibrium. In the latter case, of debt shrinking to zero in real value, agents would see their wealth steadily declining, while their tax obligations remained constant in real terms. Assuming they understand that the government will not lend to them, at least not in indefinitely large amounts, they will see their consumption as out of line with their wealth and income and will try to increase saving. This will create deflationary pressure and bring wealth back up to the level consistent with the stable equilibrium.

This type of equilibrium, with interest rate policy not keeping pace with inflation, primary surpluses not reacting to the level of real debt, are a standard result in this type of model, but the policies they assume do not look like monetary and fiscal policy in most economies. With the types of policies usually assumed (like those in the main text of this paper), the upward explosive solutions $(\kappa>0)$ do not increase or decrease private wealth. That 
remains stable because of the fiscal rule. These paths make the price level rise at a more rapid than exponential rate, and may even send it to infinity (i.e. a state of valueless money) in finite time. But along these paths private agents see no reason to change their behavior. In this paper's models, any initial price level above that consistent with the $\kappa=0$ stable solution corresponds to one of these explosive equilibrium paths.

The downward explosive solutions correspond to initial price levels below that consistent with the stable solution. They, too, leave private wealth stable. However, because of the zero lower bound, they do not imply more than exponentially downward explosion of the price level. Each initial price level below the stable-equilibrium one corresponds to a path of interest rates that declines steadily and hits the zero lower bound in finite time earlier, the lower the initial price level. Once there, as we have assumed, monetary policy simply keeps $r=0$. This implies, with fixed $\rho$, that prices decline at the constant exponential rate $-\rho$.

The upward explosive solutions are clearly undesirable - they increase transactions costs as real balances dwindle away, yet real balances in the model have no resource cost. The deflationary solutions may seem not so bad. Once $r=0$ is reached, demand for money is satiated, transactions costs are minimized, and Friedman's "optimum quantity of money" as been achieved. Of course in a model with downward nominal rigidities, this could still be a problem. But more importantly, the indeterminacy of the price level in this deterministic model would correspond to the existence of "sunspot equilibria", continual arbitrary random fluctuations in the price level, in any stochastic version of the model. In any economy with nominal contracting, such fluctuations would be costly.

So it is desirable to find policies that guarantee a unique price level, and to be realistic we should find ones that let monetary policy look like a standard Taylor rule with $\theta_{\pi}>1$ in the neighborhood of the steady state. The 
way the $r=\bar{r}, \tau=\bar{\tau}$ policy guarantees uniqueness is by making the private sector understand that when the price level is too low, real government debt becomes greater than the discounted present value of future taxes, giving them room to increase spending, and when the price level is too high, their debt holdings fall below their tax obligations, requiring them to reduce spending. Any fiscal policy with this characteristic will guarantee uniqueness of the price level.

On a path with upwardly explosive inflation, Taylor rule monetary policy, and standard "passive" fiscal policy, real debt tends steadily toward a finite steady-state value despite the explosive inflation. This means that this fiscal policy requires upwardly explosive nominal deficits to keep real debt stable despite inflation's tendency to shrink it. Any fiscal policy that commits to keeping nominal deficits smaller than this, by increasing taxes (or shrinking spending) as inflation grows, at least when it grows above some critical level, will make the explosive price path unsustainable. Such a policy will make people realize that whenever prices rise above the stableequilibrium level, the future path of prices implied by the explosive paths will make discounted future primary surpluses (and hence tax obligations) rise above the current real value of the debt.

That budget deficits might be cut (and primary surpluses thereby increased) during an explosive inflation is eminently plausible. Policy to eliminate the deflationary indeterminacies is not quite so obvious. A fiscal policy that makes $\tau$ respond linearly, even with a tiny positive coefficient, to the inflation rate, will eliminate the upward explosions. But the downward paths do not explode; they just settle into a constant deflation rate. A positive coefficient on inflation in the rule setting $\tau$ only increases the steady state level of real debt as deflation proceeds. A stronger reaction is required to eliminate the deflation. For example, a fiscal policy that responds, even with a tiny positive coefficient, to deviation of the price level 
from its steady state value would work. It would imply eventually increasing primary deficits as the price level declined, which would achieve the result that, whenever the price level started out too low, people would see that the deflationary path puts their discounted tax obligations below their government bond wealth, leading them to spend and extinguish the deflationary path.

There is a lesson here for the advanced economies that have recently struggled with long periods of slow growth and low inflation or deflation. This is an expected result if fiscal policy is not committed to counter deflation with low or negative primary surpluses, maintained until the deflation disappears. While it seems likely that policy makers understand the need for fiscal discipline in the face of inflation, recent history suggests they do not understand the need for a strong commitment to fiscal expansion in the face of deflation.

\section{APPENDix B. RULE FOR REMitTANCES}

The central bank is assumed to follow a rule for remittances, which embodies two principles: i) remittances cannot be negative, ii) whenever positive, remittances are such that the central bank capital measured at historical costs remains constant in nominal terms over time, that is: ${ }^{27}$

$$
\tilde{K}=\left(\tilde{q} B^{C}-V-M\right) e^{n t}=\text { constant. }
$$

The historical price $\tilde{q}$ evolves according to

$$
\dot{\tilde{q}}=(q-\tilde{q}) \max \left\{0, \frac{\dot{B}^{C}}{B^{C}}+\delta+n\right\}
$$

where the max operator is there because $\tilde{q}$ changes only if the central bank is acquiring assets (recall that bonds depreciate at a rate $\delta$ and that $B^{C}$ is defined in per capita terms, so that $\dot{B}^{C}=-(\delta+n) B^{C}$ implies that the central

\footnotetext{
${ }^{27}$ Hall and Reis (2013) use a similar rule, but measure capital at market prices.
} 
bank is letting its assets mature). Differentiating condition (40) above and using the central bank's budget constraint (23), one obtains a condition for nominal remittances:

$$
P \tau^{C}=(\chi-\delta(\tilde{q}-1)) B^{C}+\left(\dot{\tilde{q}}-(q-\tilde{q})\left(\frac{\dot{B}^{C}}{B^{C}}+\delta+n\right)\right) B^{C}-r V .
$$

This condition resembles closely the accounting practice of central banks. The first term, $(\chi-\delta(\tilde{q}-1)) B^{C}$, measures coupon income $\chi$ net of the amortization of historical costs $\delta(\tilde{q}-1)$, times the par value of bonds $B^{C}$. The second term equals the realized gains/losses, $-(q-\tilde{q})\left(\frac{\dot{B}^{C}}{B^{C}}+(\delta+n)\right) B^{C}$, from assets sales (that is, $\frac{\dot{B}^{C}}{B^{C}} \leq-(\delta+n)$ ), since in this case $\dot{\tilde{q}}=0$. When the central bank is acquiring assets $\left(\frac{\dot{B}^{C}}{B^{C}}>-(\delta+n)\right)$ this second term is zero because $\dot{\tilde{q}}$ and $(q-\tilde{q})\left(\frac{\dot{B}^{C}}{B^{C}}+\delta+n\right)$ cancel each other out. The last term, $r V$, captures the interest paid on reserves. Whenever net income (the left hand side of equation 42) is negative, the central bank would have to extract negative remittances from the fiscal authority to keep its capital constant. If it cannot do this, its capital declines. Whenever internal accounting rules prevent capital from declining a deferred asset is created. Remittances remain at zero until this deferred asset is extinguished (i.e., capital is back at the original level). Hence our rule for remittances is

$$
\begin{aligned}
\tau_{t}^{C}=\max \{0, & (\chi-\delta(\tilde{q}-1)) \frac{B^{C}}{P} \\
& \left.+\left(\dot{\tilde{q}}-(q-\tilde{q})\left(\frac{\dot{B}^{C}}{B^{C}}+(\delta+n)\right) \frac{B^{C}}{P}\right)-r \frac{V}{P}\right\} \mathcal{I}_{\left\{\tilde{K} \geq \tilde{K}_{0}\right\}}
\end{aligned}
$$

where $\mathcal{I}_{\left\{\tilde{K} \geq \tilde{K}_{0}\right\}}$ is an indicator function equal to one only if current capital $\tilde{K}$ is at least as large as initial capital $\tilde{K}_{0}$ (that is, the deferred asset has been extinguished). In practice central bank's capital will not be constant over time, but will likely grow along with nominal income. This implies a net influx of resources for the central bank. At the same time a fraction of net income 
is devoted to pay dividends on this capital. ${ }^{28}$ Moreover the central bank also has operating expenses. We ignore these issues in computing the simulated path of remittances since it would further complicate the description of the remittance rule, and also quantitatively they are not very important in terms of the simulated path for remittances.

In order to compute the path for remittances implied by expression (43) we need to compute paths for $\frac{B^{C}}{P}$ and $\frac{V}{P}$. For the former, we make the following assumptions about the path of the central bank's assets $B^{C}$ :

$$
\frac{\dot{B}^{C}}{P}=\left\{\begin{array}{ll}
-(\delta+n) \frac{B^{C}}{P} & (1) \\
-(\delta+n+s) \frac{B^{C}}{P} & (2)
\end{array}, \text { for } t \leq \tilde{T}\right.
$$

where $\tilde{T}$ is the time when the size of reserves has reached the early 2008 level (adjusted for inflation, population and productivity growth), after which $\frac{B^{C}}{P}$ grows with productivity (i.e., $\frac{B^{C}}{P} e^{-\gamma t}$ is constant over time, yielding $\left.\frac{\dot{B}^{C}}{P}=\left(\gamma+\frac{\dot{P}}{P}\right) \frac{B^{C}}{P}\right)$. Under assumption (1) the central bank lets its holdings of government debt mature, while under assumption (2) it sells its assets at a rate $s$ per year (we set $s=.2$ ). Neither assumption is realistic in the case of the U.S. ( $B^{C}$ has increased in 2014!) but the point is to show that different future paths for sales can yield quite different paths for $\tau^{C}$ in the short run, even though the present value of resources remitted to the fiscal authority $\bar{\tau}^{C}$ is the same. Given remittances and the path for $\frac{B^{C}}{P}$ we use the budget

\footnotetext{
${ }^{28}$ In the U.S. the central bank's capital is a fixed fraction of the capital of the member banks, and dividends are 6\% of capital (see Carpenter, Ihrig, Klee, Quinn, and Boote (2013)). Note also that according to our notation dividends are included in $\tau^{C}$, this quantity being the total amount of resources leaving the central bank in any given period. In this sense referring to $\tau^{C}$ as "remittances" to the fiscal authority is not entirely appropriate.
} 
constraint (23) to compute the evolution of reserves in real terms:

$$
\begin{aligned}
\left(\frac{\dot{V}}{P}\right)=(r-n & \left.-\frac{\dot{P}}{P}\right) \frac{V}{P} \\
& -(\chi+\delta-(n+\delta) q) \frac{B^{C}}{P}+q \frac{\dot{B}^{C}}{P}-\left(n+\frac{\dot{M}}{M}\right) \frac{M}{P}+\tau^{C}
\end{aligned}
$$

A legitimate question (also posed by Hall and Reis (2013)) is whether a rule like (43) keeps the central bank's capital measured at market prices, namely

$$
K=\left(q B^{C}-V-M\right) e^{n t}
$$

stationary. Using the budget constraint (23) we write the evolution of detrended capital in real terms $\left(\frac{K}{P} e^{-(\gamma+n) t}\right)$ as

$$
d\left(\frac{K}{P}^{-(\gamma+n) t}\right)=(\rho-n-\gamma)\left(\frac{K}{P} e^{-(\gamma+n) t}\right)+\left(r \frac{M}{P}-\tau^{C}\right) e^{-\gamma t}
$$

So the rule that stabilizes $\frac{K}{P} e^{-(\gamma+n) t}$ is

$$
\begin{aligned}
\tau^{C}=r \frac{M}{P}+(\rho-n-\gamma) & \left(\frac{K}{P} e^{-(\gamma+n) t}\right) \\
=r & \left(q \frac{B}{P}-\frac{V}{P}\right)-\left(\frac{\dot{P}}{P}+n+\gamma\right)\left(\frac{K}{P} e^{-(\gamma+n) t}\right) .
\end{aligned}
$$

This rule has quite different implications for remittances relative to the rule (43) outside of steady state, but at steady state the two coincide. In fact, at steady state $\tilde{q}=q=1, K=\tilde{K}$, and $\chi=\bar{r}$, hence the term $r\left(q \frac{B}{P}-\frac{V}{P}\right)$ coincides with the right hand side of expression (43). The remaining term $(\pi+n+\gamma)\left(\frac{K}{P} e^{-(\gamma+n) t}\right)$ accounts for the fact that capital increases with inflation, productivity, and population growth (as discussed above), a factor which we ignore in (43). If we did properly account for it, expressions (48) and (43) would be consistent with each other at least at steady state. 
Appendix C. Ruling OUt DeVIATIONS FROM High $\bar{\pi}$ EQUILIBRIUM

In section VIII we claim that any inflation target $\tilde{\pi}>.02$ satisfying equation (39) with equality, which we repeat here for convenience:

$$
\frac{q_{0}(\tilde{\pi}) B_{0^{-}}^{C}-V_{0}(\tilde{\pi})}{P_{0}(\tilde{\pi})}+\operatorname{PDVS}_{0}(\tilde{\pi})=0
$$

for an initial level of the balance sheet $B_{0^{-}}^{C}$ are equilibria in a game where the central bank's objective is to choose $\bar{\pi}=.02$, but is constrained by the lack of fiscal support $\left(\tau_{t}^{C} \geq 0\right.$ in all future periods $t \geq 0$, implying that the left hand side of the intertemporal constraint (24) must be non-negative for all $t \geq 0$ ) and by the equilibrium conditions (11), (12), (24), (29), (30), (32), (33). As reminder, in equation (39) the variables $q_{0}(\tilde{\pi}), P_{0}(\tilde{\pi}), V_{0}(\tilde{\pi})$, and $P D V S_{0}(\tilde{\pi})=\int_{0}^{\infty}\left(\frac{\dot{M}_{t}}{M_{t}}+n\right) \frac{M_{t}}{P_{t}} e^{-\int_{0}^{t}\left(\rho_{s}-n\right) d s} d t$ are the time 0 asset price, price level, reserves, and present discounted value of seigniorage, respectively, implied by the inflation target $\tilde{\pi}$. All these quantities are computed as described in section VI.

Now imagine that the private sector expects the central bank to follow the inflation target $\tilde{\pi}$, but the central bank tries to follow instead the target $\hat{\pi}<\tilde{\pi}$. We will show that this implies a present discounted value of seigniorage $\operatorname{PDVS}_{0}(\hat{\pi})<P D V S_{0}(\tilde{\pi})$, and therefore a violation of the solvency constraint.

Call $\tilde{x}_{t}$ and $\hat{x}_{t}$ the path of variable $x$ under the inflation target $\tilde{\pi}$ and under the deviation $\hat{\pi}$, respectively. Since the public expectations are formed under the belief that the central bank's inflation target is $\tilde{\pi}$, the Fisher equation (11) pins down the interest rate:

$$
\hat{r}_{t}=\rho_{t}+\tilde{\pi}_{t}=\tilde{r}_{t}
$$


where for ease of notation we refer in this section to $\frac{\dot{P}}{P}$ as $\pi_{t}$. Note that given that the interest rate equals $\tilde{r}_{t}$, transaction costs (and therefore consumption $\left.\hat{C}_{t}\right)$, money demand $\frac{\hat{M}_{t}}{P_{t}}$, and velocity $\hat{v}_{t}$ are the same as $\tilde{C}_{t}, \frac{\tilde{M}_{t}}{P_{t}}$, and $\tilde{v}_{t}$, respectively. Inflation is pinned down by the Taylor rule (5) both in equilibrium:

$$
\dot{\tilde{r}}_{t}=\theta_{r} \cdot\left(\tilde{\rho}+\tilde{\pi}+\theta_{\pi}\left(\tilde{\pi}_{t}-\tilde{\pi}\right)-\tilde{r}_{t}\right),
$$

and under the deviation:

$$
\dot{\tilde{r}}_{t}=\theta_{r} \cdot\left(\tilde{\rho}+\hat{\pi}+\theta_{\pi}\left(\hat{\pi}_{t}-\hat{\pi}\right)-\tilde{r}_{t}\right) .
$$

Since the left hand side of the two expressions is the same, it has to be that

$$
\hat{\pi}+\theta_{\pi}\left(\hat{\pi}_{t}-\hat{\pi}\right)=\tilde{\pi}+\theta_{\pi}\left(\tilde{\pi}_{t}-\tilde{\pi}\right)
$$

or $\hat{\pi}_{t}=\tilde{\pi}_{t}-\frac{\left(\theta_{\pi}-1\right)}{\theta_{\pi}}(\tilde{\pi}-\hat{\pi})<\tilde{\pi}_{t}$. From equation (30) $\frac{\hat{\dot{M}}_{t}}{M_{t}}<\frac{\tilde{M}_{t}}{M_{t}}$, implying that

$$
\begin{aligned}
\operatorname{PDVS}_{0}(\hat{\pi})=\int_{0}^{\infty}\left(\frac{\hat{\mathrm{M}}_{t}}{M_{t}}+n\right) \frac{\hat{M}_{t}}{P_{t}} e^{-\int_{0}^{t}\left(\rho_{s}-n\right) d s} d t< \\
\quad \operatorname{PDVS}_{0}(\tilde{\pi})=\int_{0}^{\infty}\left(\frac{\tilde{M}_{t}}{M_{t}}+n\right) \frac{\tilde{M}_{t}}{P_{t}} e^{-\int_{0}^{t}\left(\rho_{s}-n\right) d s} d t .
\end{aligned}
$$

Since $P D V S_{\tau}(\tilde{\pi})$ satisfies equation (39) by the definition of $\tilde{\pi}, P D V S_{\tau}(\hat{\pi})$ does not. 
Appendix D. Additional TABles AND Figures

TABLE A-1. Central bank's resources under different simulations

$\begin{array}{ccccccc}(1) & (2) & (3) & (4) & (5) & (6) & (7) \\ q B / P & \text { PDV } & (1)+(2) & \begin{array}{c}\bar{\tau}^{C} \\ \text { (average } \\ \text { remittance) }\end{array} & \mathrm{q} & \Delta M / P & \bar{B} / B \\ -V / P & \text { seigniorage }\end{array}$

Baseline calibration

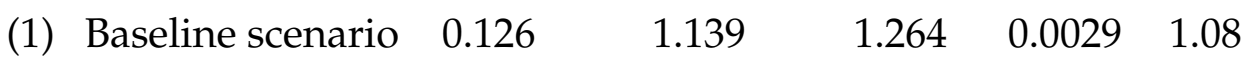

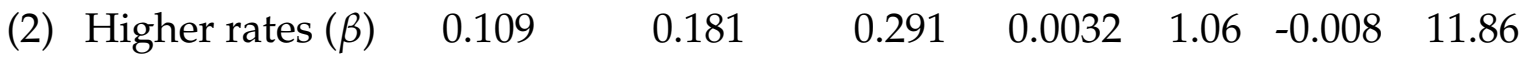

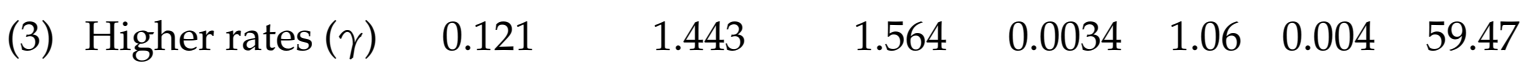

$\begin{array}{llllllll}\text { (4) Inflation scare } & 0.009 & 0.692 & 0.701 & 0.0023 & 0.85 & -0.039 & 4.06\end{array}$

$\begin{array}{llllllll}\text { (5) } \text { Explosive path } & 0.049 & 0.466 & 0.515 & 0.0012 & 0.85 & -0.001 & 3.19\end{array}$

Higher $\theta_{\pi}$

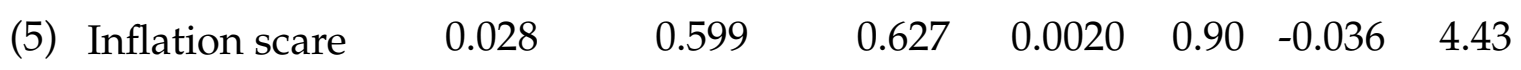

$\begin{array}{llllllll}\text { (7) } \text { Explosive path } & -0.030 & 0.175 & 0.145 & 0.0003 & 0.61 & -0.001 & 1.30\end{array}$

Lower $\theta_{\pi}$

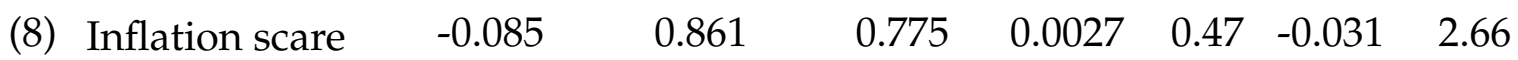

$\begin{array}{lllllllll}(9) & \text { Explosive path } & 0.115 & 6.806 & 6.922 & 0.0166 & 1.05 & 0.001 & 198.83\end{array}$ 
TABLE A-2. Central bank's resources under different simulations - Money demand estimated on pre-2008 data

(1)

(2)

$\begin{array}{lc}q B / P & P D V \\ -V / P & \text { seigniorage }\end{array}$

(3)

(4)

\begin{tabular}{lllllll}
\hline \hline \multicolumn{2}{c}{ Baseline calibration } \\
(1) Baseline scenario & 0.126 & 1.159 & 1.285 & 1.08 & \\
(2) Inflation scare & -0.044 & 0.597 & 0.554 & 0.85 & 3.42 \\
(3) Explosive path & 0.047 & -0.129 & -0.081 & 0.85 & 0.66 \\
\cline { 2 - 6 } Higher $\theta_{\pi}$ & & & & & \\
(4) Inflation scare & -0.023 & 0.384 & 0.361 & 0.90 & 2.97 \\
(5) Explosive path & -0.031 & -0.160 & -0.191 & 0.61 & 0.60 \\
\hline Lower $\theta_{\pi}$ & & & & & \\
(5) Inflation scare & -0.142 & 0.856 & 0.714 & 0.47 & 2.53 \\
(7) Explosive path & 0.113 & 0.674 & 0.787 & 1.05 & 23.49 \\
\hline
\end{tabular}


Figure A-1. Money Demand and the Laffer Curve - Money demand estimated on pre-2008 data
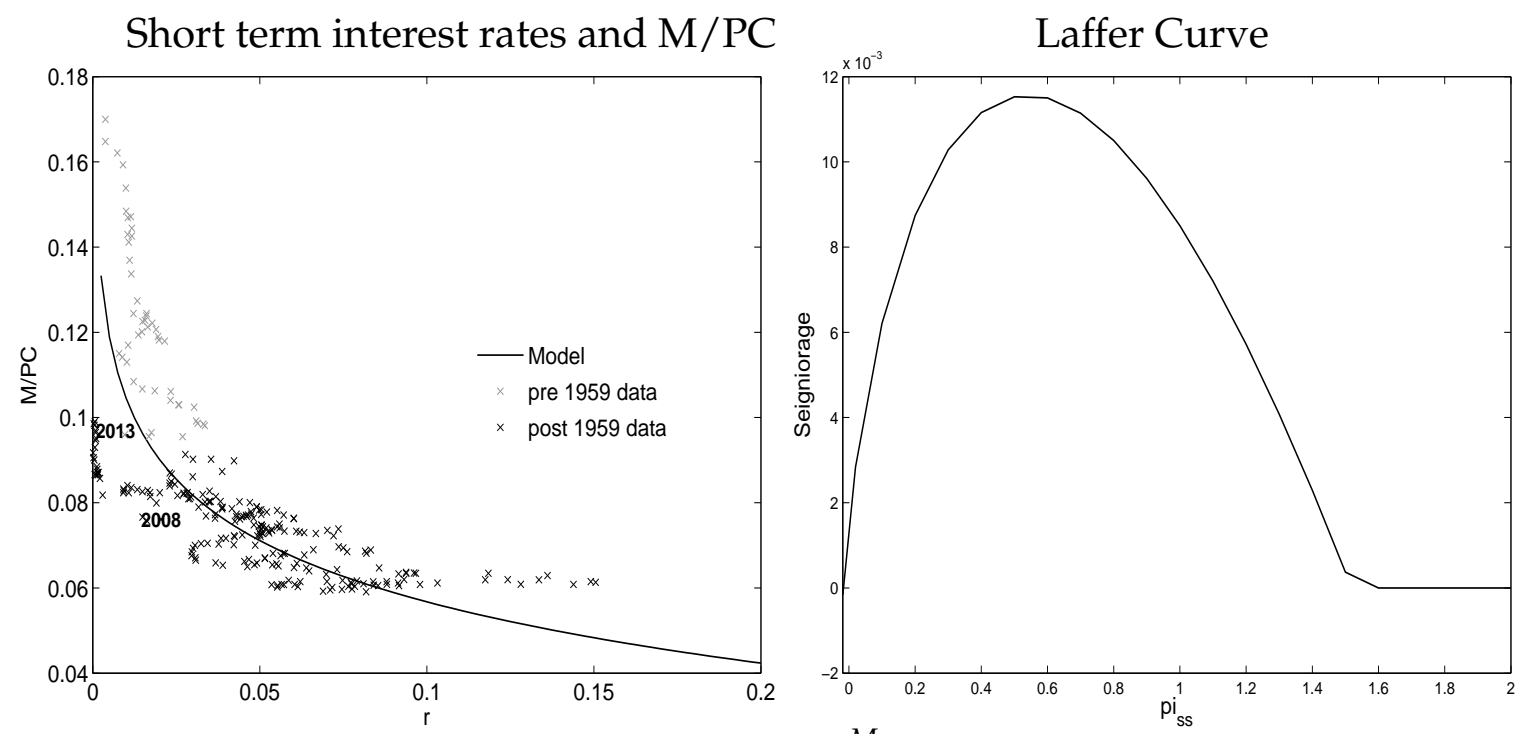

Notes: The left panel shows a scatter plot of quarterly $\frac{M}{P C}=v^{-1}$ and the annualized 3-month TBill rate (blue crosses are post-1959 data, and green crosses are 1947-1959 data) together with relationship between inverse velocity and the level of interest rates implied by the model (solid black line). The right panel shows seigniorage as a function of steady state inflation.

\section{FIGURE A-2. Money Demand Elasticity} 1959-2013 sample (baseline)
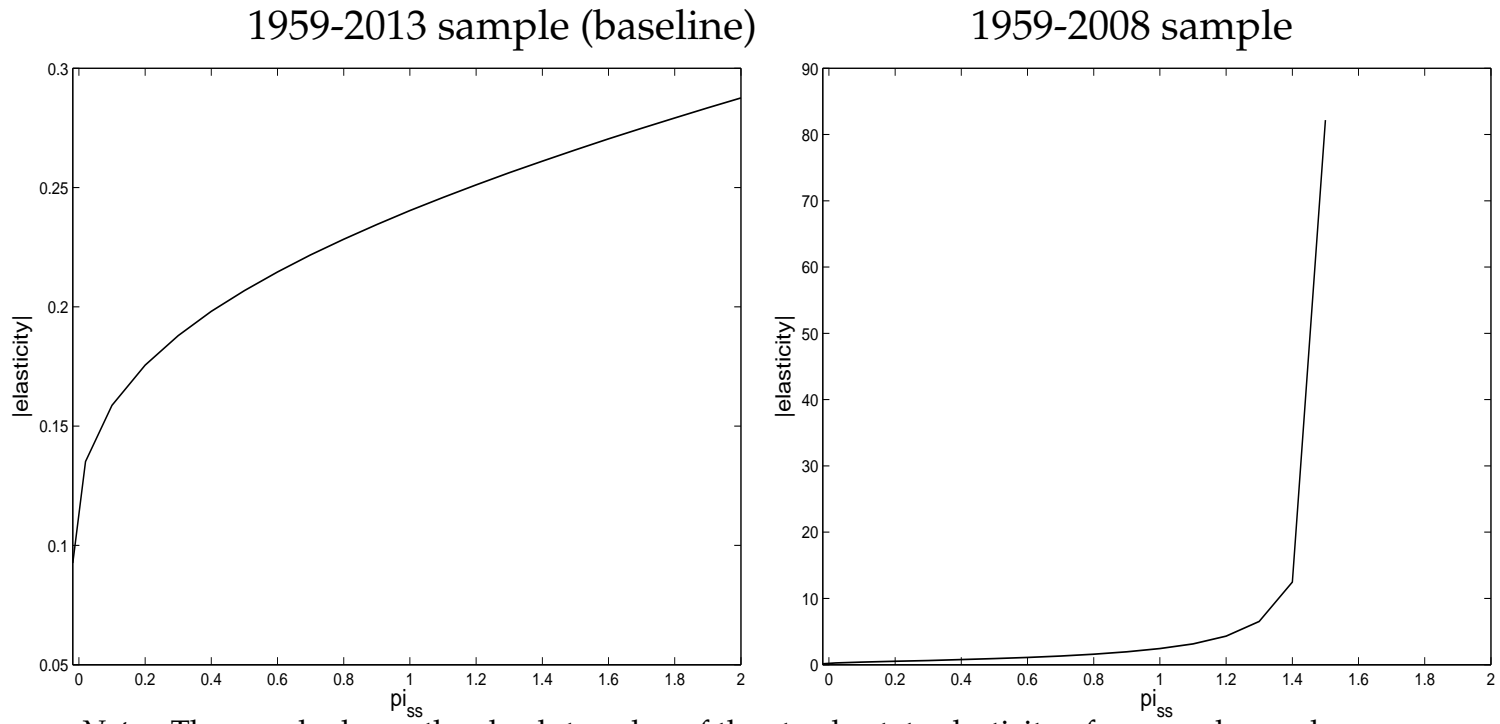

Notes: The panels shows the absolute value of the steady state elasticity of money demand ( $\left.\left|\frac{d \log M / P}{d \log r}\right|\right)$ implied by our transaction cost functions under the baseline estimation (left panel) and under the estimation on pre-2008 data (right panel) . 


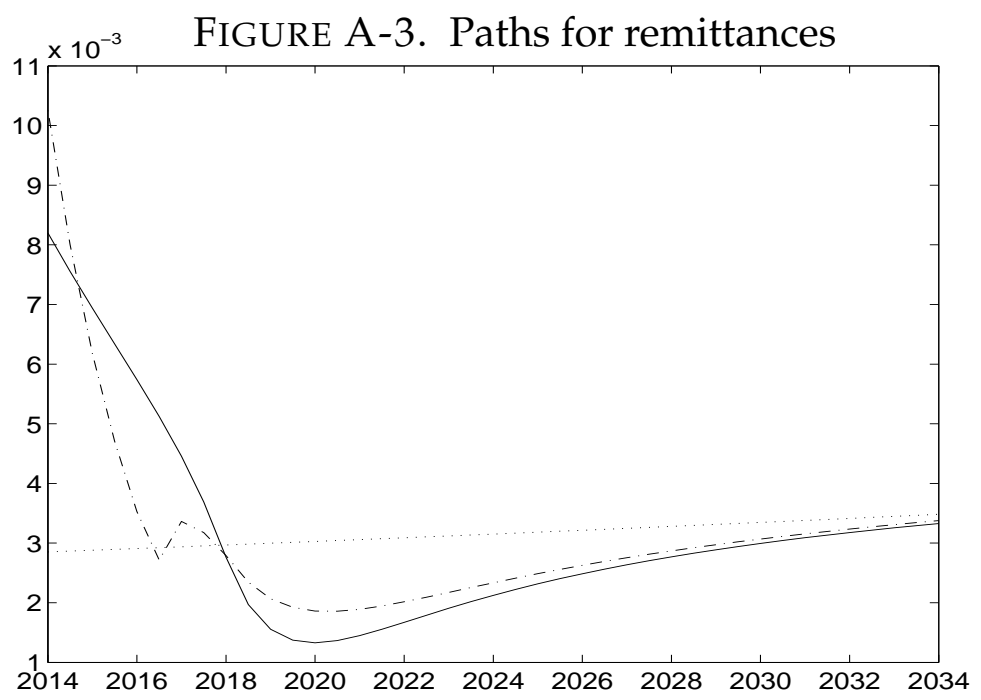

Notes: The figure shows remittances under the baseline scenario under two assumptions for the path of assets $B^{C}$ : under the first assumption (solid line) the central bank lets its assets depreciate, while in the second one (dashed-and-dotted line) it actively sells assets at a rate of 20 percent per year.

FIGURE A-4. "Inflation scare" and "explosive paths" scenarios: The effect on inflation under different inflation responses in interest rate rule

Inflation scare

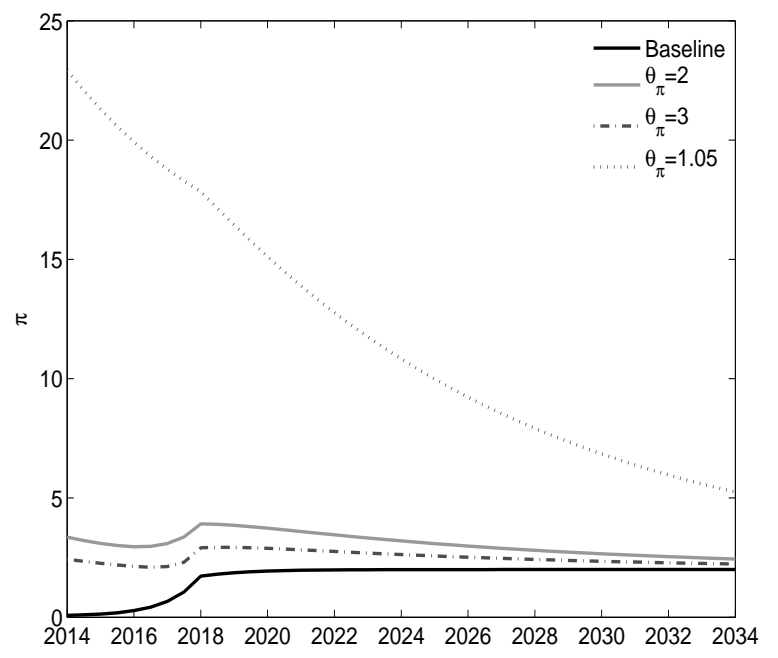

Explosive paths

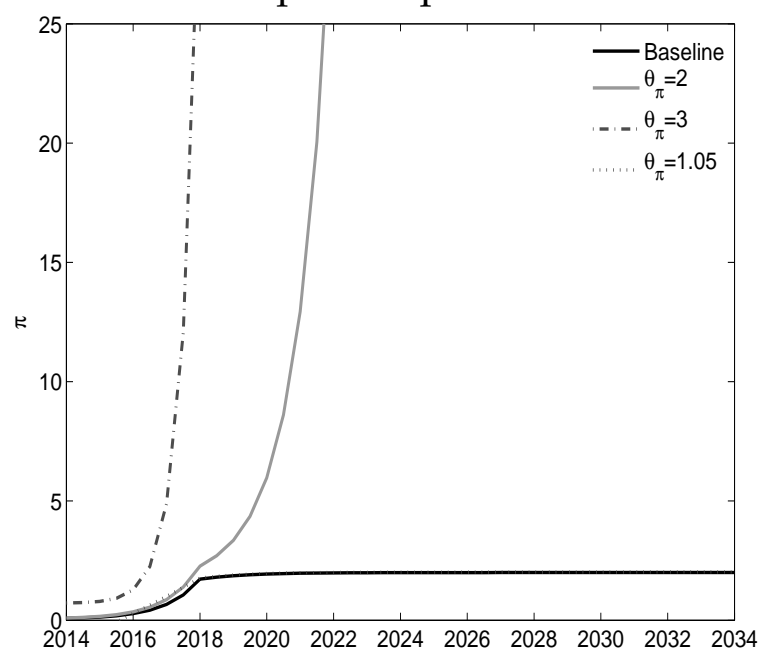

Notes: The panels show the projected path of nominal short term rates for the "inflation scare" (left panel) and the "explosive path" scenario (right panel, with $\kappa=10^{-4}$ ) under different inflation responses in interest rate rule (solid gray: $\theta_{\pi}=2$, dash-and-dotted gray: $\theta_{\pi}=3$; dotted gray: $\theta_{\pi}=1.05$ ) together with the baseline projections (solid black). 
FIGURE A-5. Self-fulfilling solvency crises, return to the ZLB

case $(\kappa<0)$

Threshold Balance Sheet Limits
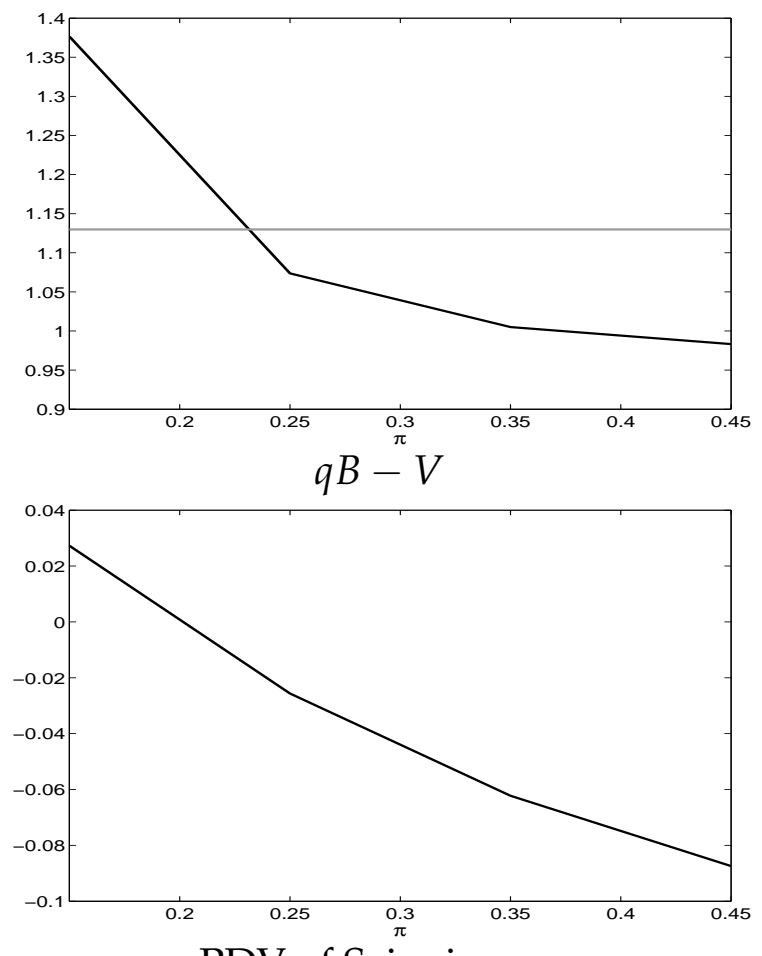

PDV of Seigniorage

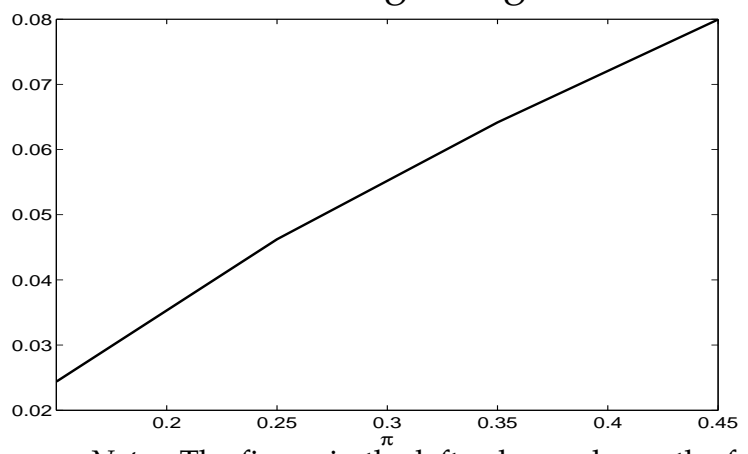

Interest Rates for $\tilde{\pi}=.35$

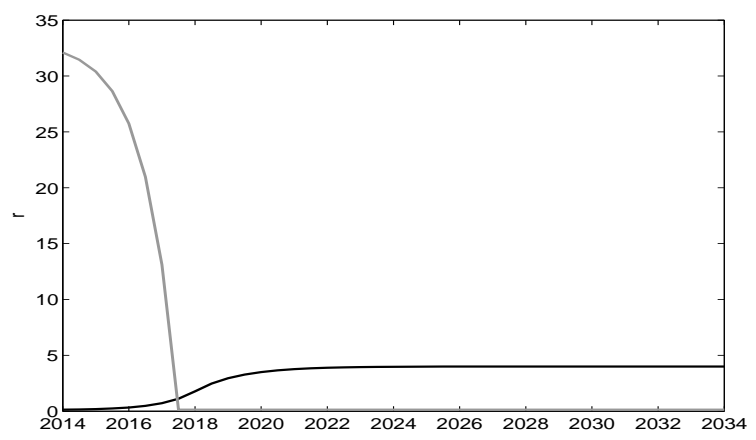

Inflation for $\tilde{\pi}=.35$

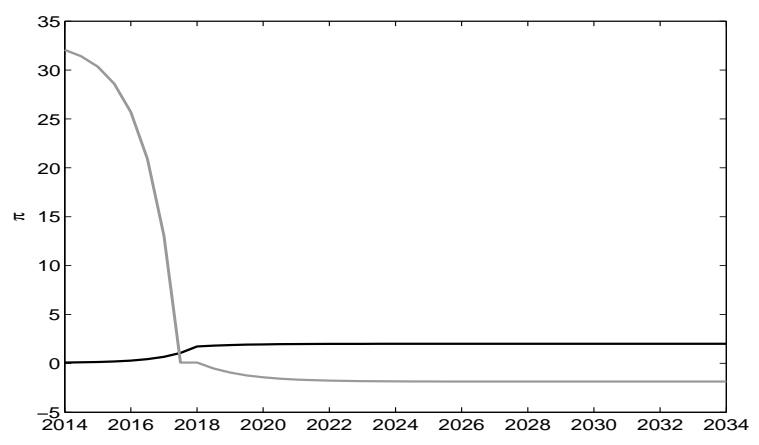

Seigniorage for $\tilde{\pi}=.35$

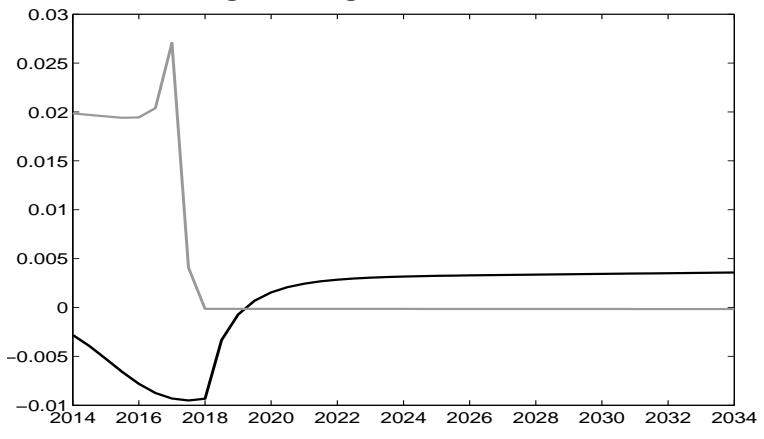

Notes: The figure in the left column shows the following quantities as a function of inflation target expected by the public $(\tilde{\pi}): 1$ ) Top panel: the solid black line shows the balance sheet level $\bar{B} / B$ (relative to the end-of-2013 level reported in Table 3) for which multiple equilibria are possible, and the gray horizontal line denotes the level of the balance sheet as of January 29 2015; 2) Middle panel: the level of $q B-V$ as a fraction of income for the current balance sheet size under alternative scenarios; 3) Bottom panel: the level of seigniorage as a fraction of income for the case where the central bank validates the public's expectations (solid black line). The panels in the right column show the projected path of nominal short term interest rates (top), inflation (middle), and seigniorage (bottom) under the baseline scenario (solid black) and under one the multiple equilibrium scenario (solid gray) obtained by setting $\tilde{\pi}=.35$, and $\kappa<0$. The value of $\kappa$ in all these plots is chosen so that the zero lower bound $\underline{r}$ is reached hit at time $t=3.5$. 
E-mail address: sims@princeton. edu

E-mail address: marco.delnegro@ny. frb.org 